\title{
Recent Advances in Quantum Scattering Calculations on Polyatomic Bimolecular Reactions
}

\author{
Bina Fu' ${ }^{\mathrm{a}}$, Xiao Shan ${ }^{\mathrm{b}}$, Dong H. Zhang ${ }^{\mathrm{a}}$ and David C. Clary ${ }^{\mathrm{b}}$ \\ a State Key Laboratory of Molecular Reaction Dynamics and Center for Theoretical \\ and Computational Chemistry, Dalian Institute of Chemical Physics, Chinese \\ Academy of Sciences, Dalian 116023, China. Email: bina@dicp.ac.cn and \\ zhangdh@dicp.ac.cn \\ b Physical and Theoretical Chemistry Laboratory, Department of Chemistry, \\ University of Oxford, South Parks Road, Oxford, OX1 3QZ, United Kingdom. \\ Email: xiao.shan@chem.ox.ac.uk and david.clary@chem.ox.ac.uk
}

\begin{abstract}
This review surveys quantum scattering calculations on chemical reactions of polyatomic molecules in the gas phase published in the last ten years. These calculations are useful because they provide highly accurate information on the dynamics of chemical reactions which can be compared in detail with experimental results. They also serve as quantum mechanical benchmarks for testing approximate theories which can more readily be applied to more complicated reactions. This review includes theories for calculating quantities such as rate constants which have many important scientific applications.
\end{abstract}



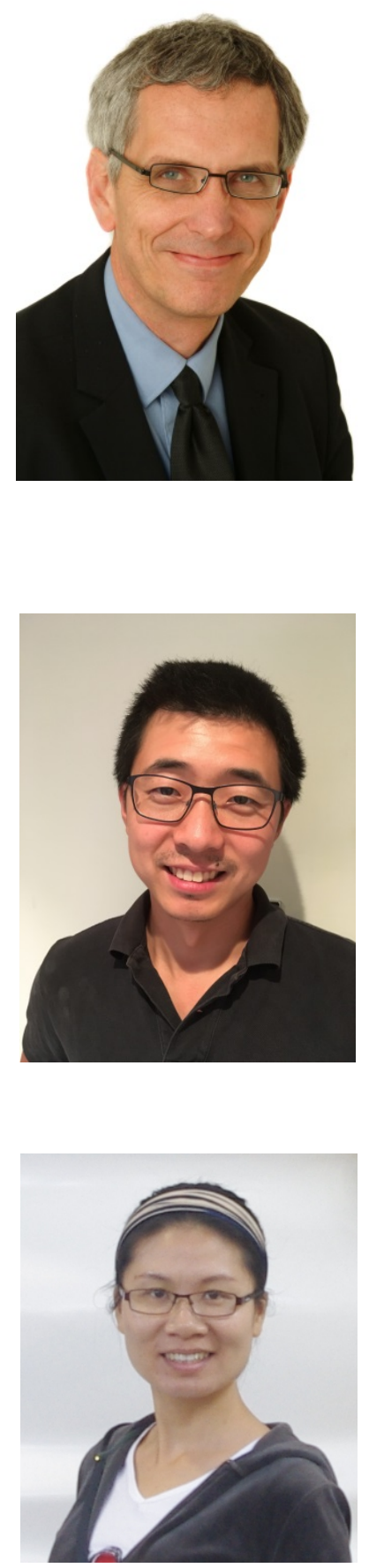

David Clary has been President of Magdalen College Oxford since 2005. He also directs a research group in the Chemistry Department at Oxford University working on the quantum theory of chemical reactions. He was the first Chief Scientific Advisor to the UK Foreign and Commonwealth Office (2009-2013) and was President of the Faraday Division of the Royal Society of Chemistry (2006-9). He was elected a Fellow of the Royal Society in 1997 and was knighted by the Queen for services to international science in 2016.

Xiao Shan undertook his Ph.D. (2006-2010) at the University of Manchester with Professor J. N. L. Connor. He has worked as a postdoctoral research associate in Professor D. C. Clary's group in the Chemistry Department at the University of Oxford since 2011. His main research interest is in application of quantum and semiclassical methods to chemical reactions involving typically more than 10 atoms, and in numerical analyses to differential cross-sections of reactive scattering process.

Bina $\mathrm{Fu}$ received her $\mathrm{PhD}$ in the State Key Laboratory of Molecular Reaction Dynamics at Dalian Institute of Chemical Physics of the Chinese Academy of Sciences in 2009, under Professor Dong H. Zhang. She then worked as a Postdoctoral Research Fellow with Professor Joel M. Bowman in the Chemistry Department at Emory University (2009-2012). In 2012, she joined Dalian Institute of Chemical Physics of the Chinese Academy of Sciences. Her research interests involve $a b$ initio potential energy surface calculations and classical and quantum dynamical studies of polyatomic chemical reactions. 


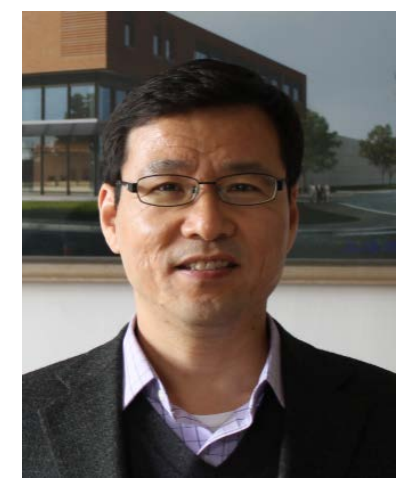

Dong Hui Zhang received his B.S. degree in physics from Fudan University, China, in 1989. He earned a Ph.D. in chemical physics from New York University in 1994. After working as a postdoctoral research fellow in New York University and the University of Chicago, he joined the National University of Singapore in 1997. He moved to Dalian Institute of Chemical Physics, CAS, in 2006. Now he is the director of the state key laboratory of molecular reaction dynamics in the institute. His primary research area is in theoretical and computational studies of chemical reactions in the gas phase and on surfaces. 


\section{Introduction}

A bimolecular chemical reaction occurs when one reactant molecule collides with another to produce new product molecules. Chemical reactivity is essentially a process of the breakage of an old chemical bond and the formation of a new chemical bond. Characterizing chemical reactions at the microscopic scale has been an important and fundamental goal of modern physical chemistry, which can provide essential mechanistic information on chemical reactions in the gas phase. The development of quantum mechanics and quantum chemistry has provided the fundamental theoretical bases for interpreting reactive collisional processes with quantum state resolution., ${ }^{1,2}$

In the Born-Oppenheimer (BO) approximation a single potential energy surface (PES) is defined as a function of nuclear coordinates. The electronic energies calculated by solving the Schrödinger equation at fixed nuclear configurations for the motion of the electrons only, constitute the PES that governs the motion of the nuclei. In the early days, obtaining accurate PESs as well as solving the Schrödinger nuclear equations accurately, however, was a formidable task, particularly for multiple electron and nuclear systems. In the past few decades, development of electronic structure theory and fitting of $a b$ initio electronic structure data has made the construction of accurate global PESs possible for multidimensional molecular systems. ${ }^{3-15}$ In addition, quantum dynamical methodologies have been greatly advanced along with the fast growth of numerical computing power. This has made full quantum dynamics calculations of chemical reactions based on first principles truly feasible. ${ }^{16-29}$

Following the development of sophisticated laser techniques and high resolution crossed molecular beam experiments, state-of-art quantum dynamics studies of a chemical reaction can be compared with the most detailed experimental measurements with full quantum-state resolution. ${ }^{30-37}$ This serves as the most rigorous test of the accuracy of both PESs and quantum mechanical theory for chemical reactions. The strong collaborations between experiment and theory have provided an understanding of the dynamics of chemical reactions at an unprecedented level. ${ }^{24,38-42}$ 
Tremendous progress has been made in quantum dynamics calculations on chemical reactions. Starting from the full-dimensional quantum dynamics study of the simplest $\mathrm{H}+\mathrm{H}_{2}$ reaction ${ }^{43}$, 44 quantum approaches have been extended to larger polyatomic reactions, such as the reactions of the $\mathrm{X}+\mathrm{YCZ}_{3} \mathrm{type}^{45-50}$. In particular in the past ten years, substantial effort has been devoted to developing theoretical methods and computational algorithms for investigating polyatomic reactions, which offer much richer dynamics information and complexity. In this review, we will focus on the recent work on quantum dynamics calculations on polyatomic reactions beyond three-atom reactions over the past decade. A variety of reactive systems of up to seven atoms are described in this section.

Quantum reactive scattering (QRS) aims to extract all observable quantities of chemical reactions by solving the time-independent or time-dependent Schrödinger equation for nuclear motion. By using hyperspherical coordinate based time-independent quantum dynamics methods, ${ }^{51}, 52$ state-to-state dynamics calculations have been accomplished for many direct atom-diatom reactions, often through the application of the ABC program. ${ }^{38,53-56}$ The time-independent quantum dynamics method based on body-frame hyperspherical democratic coordinates developed by Honvault and Launay ${ }^{57}$ was successfully used for complex-forming atom-diatom reactions. However, partly because the computational costs rise cubically with the increase of basis functions, it is difficult to extend the hyperspherical approach to larger polyatomic reactions. ${ }^{58,59}$ The solutions for the time-dependent Schrödinger equation are time evolving quantum wave packets. The wave packet approach provides a promising alternative to the time-independent methods for large-scale reactive scattering calculations because it is numerically much more efficient. $^{2,22,23,29,60-62}$ Beside, it can also give an intuitive physical picture of the reaction dynamics, which describes the evolvement of nuclei on a multidimensional PES. Therefore, the time-dependent wave packet (TDWP) approach has become the most widely used method in multidimensional quantum dynamics studies on polyatomic reactions. 
The dynamical information that can easily be obtained from the applications of the initial state-specific wave packet (ISSWP) method is the initial state-selected total reaction probabilities and cross sections, which can be used to further evaluate the thermal rate constants, if desired. The reactant Jacobi coordinates are used to make the wave packet propagation simple in practice and the calculation is similar to that for nonreactive problems. The ISSWP method deals with an initial value problem, and all numerical effort is concentrated on a specific initial state of interest. The calculation of the action of the propagator can be done very accurately and efficiently either using the time or the Chebyshev evolution operator. ${ }^{23,61,63,64}$ The wavefunction is absorbed at the edges of the grid to avoid boundary reflections, which is accomplished by simply multiplying the wavefunction by an exponentially decaying function of a coordinate near the boundary at the end of each propagation step. The total reaction probability is obtained by integrating the flux over time.

The lack of optimal coordinates for simultaneous description of the reactant channel, strongly interacting region, and product channel is the major problem for the wave packet approach, in particular for state-to-state dynamics calculations. Large numbers of grid points and basis functions are needed to represent the global wavefunction if all the state-to-state dynamical information has to be calculated with a single set of either reactant or product Jacobi coordinates. Both reactant and product coordinates were used to investigate the state-to-state dynamics for atom-diatom reactions, where the reagent to product coordinate transformation is carried out at one time step around the transition state region. ${ }^{65-71}$ However, this methodology is very difficult when applied to larger polyatomic reactions. The reactant-product decoupling (RPD) approach, which was proposed by Zhang and coworkers in $1996^{72}$, has been successfully employed in recent state-to-state calculations beyond three-atom reactions. ${ }^{24,73-76}$ In this approach, the wave packet is first propagated in the reactant channel, and the no-return part entering the product channel is extracted by an adsorbing potential and transformed into the product coordinates, and further propagated into the product asymptote. In addition, it is actually not necessary to absorb the wavefunction in reactant coordinates at every propagation step, instead one 
can perform such an absorption after multiple propagation steps, which makes the RPD approach more appealing for state-to-state dynamics studies. ${ }^{73-77}$ The RPD method solves, to a large extent, the problem of the choice of coordinates, in particular for direct activated reactions with barriers. A TDWP method was developed based on the RPD scheme to efficiently calculate the fully converged differential cross sections (DCSs) for four-atom reactions with all six degrees of freedom treated exactly. The computed DCS for the $\mathrm{HD}+\mathrm{OH} \rightarrow \mathrm{H}+\mathrm{HOD}$ reaction are in excellent agreement with a crossed-molecular beam experiment, representing a milestone in quantum dynamics studies because of the first complete state-to-state treatment beyond three-atom reactions. ${ }^{24}$

A new transition-state wave packet (TSWP) approach to study the reactive quantum scattering at the state-to-state level has been proposed by Manthe and coworkers $^{78,79}$, which is based on the quantum transition-state theory of Miller ${ }^{80}$. In this approach, a few transition-state wave packets, defined by the eigenfunctions of the thermal flux operator located near the transition state, are propagated into the asymptotic regions of the reactant and product channels separately using the corresponding Jacobi coordinates. The entire $S$-matrix for all energies can be assembled from the corresponding cross-correlation functions for all arrangement channels. The propagations are essentially of the inelastic type, within one set of coordinates, which alleviates the coordinate problem. The transformation from the initial transition-state wave packets into the appropriate Jacobi coordinates is performed only once. The grid/basis for the propagation is expected to be smaller than that demanded in conventional wave packet state-to-state calculations. The TSWP method has been successfully applied with both the multiconfiguration time-dependent Hartree (MCTDH) $)^{49,78,81}$ and traditional grid/basis framework ${ }^{82-84}$ in exploring the state-to-state dynamics for atom-diatom reactions and some reactions of beyond three atoms. Nevertheless, the number of TSWPs can increase very rapidly with energy, particularly for heavy systems.

In Sections II-V of this review we will discuss TDWP calculations on polyatomic chemical reactions beyond three-atom reactions published in the last ten years. We 
first consider four-atom reactions and then describe calculations on reactions of up to seven atoms. Approximate methods for reactions beyond six atoms are then discussed in Section VI. We conclude in Section VII with a brief discussion of future prospects for quantum dynamics calculations on chemical reactions.

\section{Four-atom reactions}

\section{1. $\mathrm{OH}+\mathrm{H}_{2} \leftrightarrow \mathrm{H}+\mathrm{H}_{2} \mathrm{O}$}

The reaction of $\mathrm{OH}$ with $\mathrm{H}_{2}$ is a prototype reaction for $\mathrm{H}$ atom abstraction by an $\mathrm{OH}$ radical to form water as a product. It is important in combustion chemistry, especially in that of hydrogen, as well as in the chemistry of the atmosphere. ${ }^{85,86}$ The reverse reaction $\mathrm{H}+\mathrm{H}_{2} \mathrm{O}$ has been studied widely as a prototype system for mode-specific chemistry. ${ }^{87-92}$ As three of the four atoms in the reactive system are hydrogens, the $\mathrm{OH}_{3}$ system and its isotopically substituted analogs are ideal candidates for high quality electronic structure calculation of the PES as well as for accurate QRS study.

In the past decades, a number of PESs, including WDSE, OC, ${ }^{93,}{ }^{94} \mathrm{WSLFH}^{95}$, YZCL2 ${ }^{96}, \mathrm{XXZ}^{24}$ and $\mathrm{CXZ}^{11} \mathrm{PESs}$, have been constructed for the reaction system using different methods. Extensive QRS studies have been carried out on these PESs to investigate the dynamics of this benchmark four-atom system, and to develop methodologies to obtain state-to-state DCSs. Zhang and coworkers obtained the first full dimensional state-to-state reaction probabilities for the total angular momentum $J$ $=0$ on the WDSE PES by transforming the wave packet in the transition state region from reactant coordinates to product coordinates. In recent years, the quantum wave packet method based on the RPD approach was used by Althorpe and coworkers to obtain the state-to-state reaction probability for the $\mathrm{H}_{2}+\mathrm{OH} \rightarrow \mathrm{H}_{2} \mathrm{O}+\mathrm{H}$ reaction in full dimensions for $J=0$ on the old WSLFH PES ${ }^{73,76,97,98}$. Zhang and coworkers reported the full-dimensional DCSs for the $\mathrm{HD}+\mathrm{OH} \rightarrow \mathrm{H}_{2} \mathrm{O}+\mathrm{D}$ reaction on the XXZ PES, employing the TDWP approach based on the RPD scheme. Excellent agreement was achieved for the first time for a four-atom reaction between the theoretical DCSs and 
high-resolution crossed-molecular beam experimental results on the system, as shown in Fig. 1. This achievement indicates it is feasible to calculate complete dynamical information for some simple four-atom reactions without any dynamical approximation. It was found that the $\mathrm{H}_{2} \mathrm{O}$ product is strongly backward scattered with a large fraction of the available energy deposited into $\mathrm{H}_{2} \mathrm{O}$ internal excitation, which is consistent with a direct abstraction mechanism via a nearly collinear transition state. The RPD scheme based TDWP method was further applied to compute DCSs for some isotopically substituted reactions, $\mathrm{HD}+\mathrm{OH} \rightarrow \mathrm{H}_{2} \mathrm{O}+\mathrm{D}, \mathrm{D}_{2}+\mathrm{OH} \rightarrow \mathrm{HOD}+\mathrm{D}$ and $\mathrm{H}_{2}+\mathrm{OH} \rightarrow \mathrm{H}_{2} \mathrm{O}+\mathrm{H}^{75,99-101}$

The TSWP method ${ }^{78,79}$ was developed by Guo and coworkers to calculate the state-to-state $S$-matrix and reaction probabilities for $\mathrm{H}_{2} / \mathrm{D}_{2}+\mathrm{OH} \rightarrow \mathrm{H} / \mathrm{D}+\mathrm{H}_{2} \mathrm{O} / \mathrm{HOD}$ reactions with $J=0 .{ }^{83,102}$ Based on a local-mode picture, it was found that the energy flow along the reaction coordinate into the newly formed $\mathrm{OH}$ bond and the sequestration of the vibrational energy in the $\mathrm{OH}$ spectator moiety result in the vibrational excitation of the $\mathrm{H}_{2} \mathrm{O}$ product. The detailed analysis provided a unified interpretation of the seemingly contradicting experimental observations for this reaction. ${ }^{88,91}$ Besides, the reaction-coordinate-based (RCB) method was employed to extract the state-to-state $S$-matrix and reaction probabilities for $\mathrm{HD}+\mathrm{OH}$ and $\mathrm{H}+\mathrm{H}_{2} \mathrm{O}$ reactions. Recently, a new RCB method for computing $S$-matrix elements and DCSs for $\mathrm{H}_{2}+\mathrm{OH} \rightarrow \mathrm{H}+\mathrm{H}_{2} \mathrm{O}$ was presented ${ }^{103}$. It involves the interpolation of the TDWP, using a collocation method at selected time intervals on the product grid that naturally defines the product asymptotic states. This approach was successfully demonstrated in atom-diatom reactions, ${ }^{104}$ and was generalized to the calculation of the $S$-matrix elements and corresponding DCSs for tetratomic systems.

The $\mathrm{H}+\mathrm{H}_{2} \mathrm{O} \rightarrow \mathrm{H}_{2}+\mathrm{OH}$ reaction and its isotopically substituted analogies are considered as the simplest atom-triatomic reactions. There are three vibrational modes of the water reagent, i.e., the symmetric stretching $\left(v_{1}\right)$, bending $\left(v_{2}\right)$, and asymmetric stretching $\left(v_{3}\right)$ modes, respectively. The $\mathrm{H}+\mathrm{H}_{2} \mathrm{O} \rightarrow \mathrm{H}_{2}+\mathrm{OH}$ and its isotopically substituted reactions have proven to be an excellent candidate system for 
demonstrating how the different vibrational modes of polyatomic reagents influence the reaction dynamics. In addition, this reaction system is sufficiently small to be amenable to full-dimensional quantum dynamics calculations on accurate PESs.

Crim, Zare, and co-workers carried out a series of experimental studies on the $\mathrm{H}+\mathrm{H}_{2} \mathrm{O}$ and its isotopically substituted analogies. ${ }^{87-92}$ Strong mode specific reactivity was observed in the $\mathrm{H}+\mathrm{H}_{2} \mathrm{O} / \mathrm{D}_{2} \mathrm{O}$ reactions, and strong bond selectivity was also been demonstrated in the $\mathrm{H}+\mathrm{HOD}$ reaction with a preferential cleavage of the HOD vibrationally excited bond. Stimulated further by the experiments, extensive theoretical studies were carried out on these reactions in the past decades, ranging from quasiclassical trajectory (QCT) calculations, ${ }^{105}$ reduced dimensional quantum calculations, ${ }^{106-111}$ to full-dimensional quantum dynamics studies. ${ }^{112-114}$

Recently, the ISSWP method was further developed to calculate the exact coupled-channel (CC) integral cross sections (ICSs) for $\mathrm{H}+\mathrm{H}_{2} \mathrm{O}^{115}$ and $\mathrm{H}+\mathrm{HOD}^{116}$ reactions on the YZCL2 ${ }^{96}$ and CXZ PESs, respectively. The CXZ PES is the most accurate and smooth PES available for the reaction system, ${ }^{11}$ constructed by the neural network (NN) method ${ }^{10,117,118}$ based on $17000 a b$ initio points calculated at the UCCSD(T)-F12a/AVTZ level of theory. The reactivity enhancements from different initial vibrational states of $\mathrm{H}_{2} \mathrm{O}$ and HOD were obtained, including bending excited states, first and second stretching excited states, and simultaneous excitations of both bending and stretching modes. The strong mode specificity of $\mathrm{H}^{+} \mathrm{H}_{2} \mathrm{O}$ and bond selectivity of $\mathrm{H}+\mathrm{HOD}$ as discovered in the experiments were obtained. It is consistent with the extended Polanyi rules, suggesting the vibrational excitation is supposed to be more efficient than the translational motion in promoting a reaction with a late barrier, such as the $\mathrm{H}+\mathrm{H}_{2} \mathrm{O}$ abstraction reaction.

The thermal rate constant and the contributions to this coefficient from individual vibrational states of $\mathrm{H}_{2} \mathrm{O}$ were also obtained and compared with the available experimental data. A Sudden Vector Projection (SVP) model was recently proposed in an attempt to predict mode specificity and bond selectivity from the coupling of reactant modes with the reaction coordinate at the transition state. ${ }^{119-121}$ The SVP model is capable of qualitatively predicting experimental and full dimensional 
quantum dynamical results and has been successfully applied to many reactions including the $\mathrm{H}+\mathrm{H}_{2} \mathrm{O}$ reaction.

Very recently, the first full-dimensional quantum DCSs for the $\mathrm{H}+\mathrm{H}_{2} \mathrm{O} \rightarrow$ $\mathrm{H}_{2}+\mathrm{OH}$ reaction with initial nonrotating $\mathrm{H}_{2} \mathrm{O}$ in the (000), (100) and (001) vibrational states were reported to investigate the initial vibrational excitation influences on the product state distribution and DCS. ${ }^{122,123}$ The full-dimensional state-to-state quantum calculation is carried out on the CXZ PES by using the improved RPD scheme based TDWP method. ${ }^{73,75}$ The total DCSs for the $\mathrm{H}+\mathrm{H}_{2} \mathrm{O} \rightarrow \mathrm{H}_{2}+\mathrm{OH}$ reaction with $\mathrm{H}_{2} \mathrm{O}$ initially in the (000), (100) and (001) vibrational states at three collision energies and three total energies are shown in Fig. 2. As seen, the vibrational excitations dramatically enhance the DCSs, and one quantum in the symmetric or asymmetric stretching excitation of $\mathrm{H}_{2} \mathrm{O}$ has nearly identical effects on the DCS. The energy initially deposited in stretching vibrations is much more efficient than the translational energy in promoting the reaction, but has rather similar effects on product angular distribution as the translational energy. In addition, the full-dimensional state-to-state calculations reveal that the reaction from (100) and (001) initial states of $\mathrm{H}_{2} \mathrm{O}$ produce vibrationally "cold" $\mathrm{OH}$ as the ground initial state, in agreement with the experimental observation of Zare and coworkers. ${ }^{91}$ This observation can be explained clearly by the local mode picture of $\mathrm{H}_{2} \mathrm{O}$ vibration, and reveals that the non-reacting $\mathrm{OH}$ does act as a spectator in the reaction.

\section{2. $\mathrm{H}^{\prime}+\mathrm{H}_{2} \mathrm{O} \rightarrow \mathrm{H}^{\prime} \mathrm{OH}+\mathrm{H}$}

Most of the studies of the $\mathrm{OH}_{3}$ system were done on the basis that the one of $\mathrm{OH}$ bonds in the $\mathrm{H}_{2} \mathrm{O}$ reactant is basically a spectator bond that will not be cleaved or highly excited during the reaction. Consequently, one could use a very limited vibrational basis function for the bond, or sometimes just simply freeze it in some approximate studies in order to simplify the calculations. It has been found in previous studies that one $\mathrm{OH}$ bond in the $\mathrm{H}_{2} \mathrm{O}$ reactant can be treated as a nonreactive bond for the $\mathrm{H}+\mathrm{H}_{2} \mathrm{O} \rightarrow \mathrm{H}_{2}+\mathrm{OH}$ abstraction reaction and the reverse reaction; however, both $\mathrm{OH}$ bonds should be treated as reactive bonds in order to accurately 
investigate the $\mathrm{H}^{\prime}+\mathrm{H}_{2} \mathrm{O} \rightarrow \mathrm{H}^{\prime} \mathrm{OH}+\mathrm{H}$ exchange reaction, ${ }^{124}$ due to the saddle point close to a $\mathrm{C}_{3 \mathrm{v}}$ geometry. The ICS of the $\mathrm{H}+\mathrm{D}_{2} \mathrm{O} \rightarrow \mathrm{D}+\mathrm{HOD}$ reaction was first reported in 2000, ${ }^{113}$ in which the reaction probabilities were calculated with one OD bond treated as a nonreactive bond and under the centrifugal sudden (CS) approximation.

In 2012, a full-dimensional quantum dynamics study was reported for the $\mathrm{H}+\mathrm{D}_{2} \mathrm{O} \rightarrow \mathrm{D}+\mathrm{HOD}$ reaction using the ISSWP approach on the YZCL2 PES, with both OD bonds in the $\mathrm{D}_{2} \mathrm{O}$ reactant treated as reactive bonds. ${ }^{125}$ This is the first work from which one can obtain CC results with two reactive bonds for four-atom reactions. Due to the $\mathrm{C}_{3 \mathrm{v}}$ minimum along the reaction path, a clear step-like feature is demonstrated in the CC cross sections just above the threshold, presenting the existence of shape resonance in the reaction, as shown in Fig. 3. The CC cross sections show very good agreement with the experimental results, and are a bit larger than the previous theoretical results, which confirms that the one reactive bond approximation and CS approximation together used in the previous study ${ }^{113}$ did not lead to substantial errors in the ICSs. Similar behaviors for the CC cross sections were found in later quantum dynamics studies for the $\mathrm{H}+\mathrm{H}_{2} \mathrm{O} / \mathrm{HOD}$ and $\mathrm{D}+\mathrm{H}_{2} \mathrm{O} / \mathrm{HOD}$ exchange reactions. ${ }^{126,127}$

\section{3. $\mathrm{F}+\mathrm{H}_{2} \mathrm{O} \leftrightarrow \mathrm{HF}+\mathrm{OH}$}

The $\mathrm{F}+\mathrm{H}_{2} \mathrm{O} \rightarrow \mathrm{HF}+\mathrm{OH}$ exothermic hydrogen abstraction reaction has recently become a prototype for understanding the mode specificity and product energy disposal in four-atom reactions. ${ }^{128,} 129$ This reaction has an "early" (reactant-like) barrier, and is of some importance in atmospheric chemistry and astrochemistry. The Polanyi rules for atom-diatom reactions reveal that translational energy is more effective than vibrational energy in promoting the reaction for a reaction with an "early" (reactant-like) barrier and the reverse is true for a reaction with a "late" (product-like) barrier. ${ }^{130}$ It is interesting to test the applicability of the Polanyi rules in polyatomic reactions, such as the $\mathrm{F}+\mathrm{H}_{2} \mathrm{O} \rightarrow \mathrm{HF}+\mathrm{OH}$ reaction.

The ICSs for the reaction in three fundamental vibrational modes of $\mathrm{H}_{2} \mathrm{O}$ were 
calculated both by the ISSWP and QCT approaches on an accurate global PES. ${ }^{28,119 \text {, }}$ 131, 132 The PES was fit by permutationally invariant polynomials (PIP) ${ }^{8,9}$ to large number of MRCI+Q/AVTZ energy points. ${ }^{133}$ It was found that the translational energy is more efficient in enhancing the reactivity than the vibrational excitations for this early-barrier reaction around the threshold, as shown in Fig. 4. This is consistent with the extended Polanyi rules. Only at high total energies, the excitations in vibrational modes of $\mathrm{H}_{2} \mathrm{O}$, (100), (010), (001) have higher efficacy in enhancing the reactivity of the reaction than the same amount of translational energy. The recently proposed SVP model seems to predict well the mode specificity in this reaction at high energies, but not at low energies around the threshold, as show in Fig. 4b. ${ }^{119}$

The mode specificity of the reverse $\mathrm{HF}+\mathrm{OH} \rightarrow \mathrm{F}+\mathrm{H}_{2} \mathrm{O}$ reaction was investigated $^{134}$ using the ISSWP and QCT methods on a more accurate permutationally invariant polynomial-neural network (PIP-NN) PES. ${ }^{14}$ This PES uses a set of PIPs instead of pairwise distances as input data in the neural network. Consistent with the prediction of the SVP model, it was found that the HF vibration strongly promotes the reaction, while the $\mathrm{OH}$ vibration has essentially no effect. The $\mathrm{F}+\mathrm{HOD} \rightarrow \mathrm{HF}+\mathrm{OD}$ and $\mathrm{DF}+\mathrm{OH}$ reactions were also investigated using the ISSWP method with the CS approximation. ${ }^{135}$ The results indicate that excitation of the local $\mathrm{OH}$ or OD vibrational mode enhances the cleavage of the corresponding bond. The bond selectivity is very strong at low collision energies.

The quantum mechanical characterization of state-to-state dynamics for the $\mathrm{F}+\mathrm{H}_{2} \mathrm{O} \rightarrow \mathrm{HF}+\mathrm{OH}$ is essential but is much more difficult than the extensively studied $\mathrm{H}+\mathrm{H}_{2} \mathrm{O} \leftrightarrow \mathrm{H}_{2}+\mathrm{OH}$ reaction. The full-dimensional quantum dynamics of this reaction was investigated at the state-to-state level for the first time using the TSWP method on the PIP-NN PES. ${ }^{84}$ The $J=0$ state-to-state $S$-matrix elements and reaction probabilities were obtained in that study. It was found that the $\mathrm{H}_{2} \mathrm{O}$ rotation enhances the reactivity and the product-state distribution is dominated by HF vibrational excitation while the $\mathrm{OH}$ moiety serves effectively as a spectator for $J=0$. These observations confirmed the dominant role played by the transition state in this reaction, as both the $\mathrm{H}_{2} \mathrm{O}$ rotational and $\mathrm{HF}$ vibrational modes are strongly coupled to 
the reaction coordinate at the transition state. The transition-state dominance of the reaction dynamics is also modulated by other features on the PES, such as the pre-reaction well. However, the overall reactivity should also consider the nonzero total angular momentum $J$ to discuss effects of reagent rotational excitation of the reaction. Future extensions to nonzero total angular momentum quantum numbers will yield accurate ICSs to reconsider the influences of rotational excitation.

\section{4. $\mathrm{Cl}+\mathrm{H}_{2} \mathrm{O} \leftrightarrow \mathrm{HCl}+\mathrm{OH}$}

The $\mathrm{Cl}+\mathrm{H}_{2} \mathrm{O} \rightarrow \mathrm{HCl}+\mathrm{OH}$ and its isotopically substituted reactions are of great importance in atmospheric chemistry and have also served as a prototype for understanding mode specificity and bond selectivity in reaction dynamics. ${ }^{136-138}$ This reaction is endoergic and has a "late" (product-like) barrier, which is similar to the endoergic $\mathrm{H}+\mathrm{H}_{2} \mathrm{O}$ reaction.

Recently, the ISSWP approach was employed to investigate the mode specificity of $\mathrm{Cl}+\mathrm{H}_{2} \mathrm{O} \rightarrow \mathrm{HCl}+\mathrm{OH}$ and its reverse ${ }^{139,}{ }^{140}$, and also the bond selectivity of $\mathrm{Cl}+\mathrm{HOD} \rightarrow \mathrm{HCl}+\mathrm{OD}^{141}$ on the PIP-NN PES. The ICSs of these reactions were obtained under the CS and $J$-shifting approximations, i.e., the partial wave contributions from $J>0$ are all obtained from the $J=0$ probability by shifting the energy. ${ }^{142}$ The results indicate that the $\mathrm{Cl}+\mathrm{H}_{2} \mathrm{O} \rightarrow \mathrm{HCl}+\mathrm{OH}$ reaction is enhanced strongly by excitations of the stretching modes of the $\mathrm{H}_{2} \mathrm{O}$ reactant but only weakly by bending excitations. For the $\mathrm{Cl}+\mathrm{HOD} \rightarrow \mathrm{HCl}+\mathrm{OD}$ reaction, it was found that excitation of the local $\mathrm{OH}$ vibration in the HOD reactant renders the reaction strongly bond selective, with the $\mathrm{OD} / \mathrm{OH}$ branching ratio in quantitative agreement with the experiment. ${ }^{137}$ The observed mode specificity and bond selectivity is consistent with the predictions of the recently proposed SVP model, which attributes the promotional effects of the reactant modes to their couplings with the reaction coordinate at the transition state. ${ }^{119}$ Furthermore, it was found that the vibrational excitation of the $\mathrm{HCl}$ reactant greatly enhances the reactivity while the $\mathrm{OH}$ vibrational excitation has little effect for the reverse $\mathrm{HCl}+\mathrm{OH} \rightarrow \mathrm{Cl}+\mathrm{H}_{2} \mathrm{O}$ reaction. 
The state-to-state quantum dynamics of the $\mathrm{Cl}+\mathrm{H}_{2} \mathrm{O} \rightarrow \mathrm{HCl}+\mathrm{OH}$ reaction was recently investigated for the first time in full dimensionality using the TSWP method. ${ }^{143}$ The state-to-state reactivity and its dependence on the reactant internal excitations for $J=0$ were calculated and found to share many similarities with the $\mathrm{H}+\mathrm{H}_{2} \mathrm{O} \rightarrow \mathrm{H}_{2}+\mathrm{OH}$ reaction. The strong enhancement of reactivity by the $\mathrm{H}_{2} \mathrm{O}$ stretching vibrational excitations in the reaction is attributed to the favorable energy flow into the reaction coordinate near the transition state.

\section{5. $\mathrm{O}\left({ }^{3} \mathrm{P}\right)+\mathrm{H}_{2} \mathrm{O} \rightarrow \mathrm{OH}+\mathrm{OH}$}

The mode specificity of the $\mathrm{O}\left({ }^{3} \mathrm{P}\right)+\mathrm{H}_{2} \mathrm{O} \rightarrow \mathrm{OH}+\mathrm{OH}$ reaction with a late barrier was investigated using the ISSWP method with the CS approximation, ${ }^{119}$ using the PIP PES fitted to UCCSD(T)/AVTZ energy points. ${ }^{144}$ Strong promotional effects by the stretching vibrational excitation of the $\mathrm{H}_{2} \mathrm{O}$ reactant were found, which is consistent with Polanyi rules. In addition, the symmetric stretching mode has a higher efficacy than the antisymmetric stretching mode and the bending excitation only enhances the reaction slightly.

\section{6. $\mathrm{H}+\mathrm{H}_{2} \mathrm{~S} \leftrightarrow \mathrm{H}_{2}+\mathrm{SH} / \mathrm{H}+\mathrm{H}_{2} \mathrm{~S}$}

The reaction of hydrogen atom with hydrogen sulfide is a prototypical multi-channel reaction. As discussed above for the $\mathrm{H}+\mathrm{H}_{2} \mathrm{O}$ reaction, there exist two reaction channels in the moderate energy range: the abstraction channel $\mathrm{H}+\mathrm{H}_{2} \mathrm{~S} \rightarrow \mathrm{H}_{2}$ $+\mathrm{SH}$ and the exchange channel $\mathrm{H}^{\prime}+\mathrm{H}_{2} \mathrm{~S} \rightarrow \mathrm{H}^{\prime} \mathrm{SH}+\mathrm{H}$. The $\mathrm{H}+\mathrm{H}_{2} \mathrm{~S}$ abstraction reaction plays an important role in sulfur combustion. Due to the lack of accurate global PESs of this reactive system, the dynamics was seldom investigated.

Recently, an accurate global PES for the $\mathrm{H}+\mathrm{H}_{2} \mathrm{~S}$ reaction was calculated by the PIP-NN fit to roughly 34000 high-level $a b$ initio points at the level of frozen-core UCCSD(T)-F12a/AVTZ ${ }^{145}$. The 6D ISSWP method was employed to study the mode-specific dynamics of the $\mathrm{H}+\mathrm{H}_{2} \mathrm{~S}$ reaction on the PIP-NN PES ${ }^{146}$, in which the reaction probabilities for $J>0$ were obtained using the CS approximation. The $\mathrm{H}+$ $\mathrm{H}_{2} \mathrm{~S}$ reaction prefers the abstraction channel to the exchange channel over the energy 
range studied, in sharp contrast to the findings in the $\mathrm{H}+\mathrm{H}_{2} \mathrm{O}$ reaction. In addition, the vibrational excitation is less efficient than the translational energy in promoting the reaction except at high energies. This is in sharp contrast to the mode specificity in the $\mathrm{H}+\mathrm{H}_{2} \mathrm{O} \rightarrow \mathrm{H}_{2}+\mathrm{OH}$ reaction, in which excitations in the stretching modes promote the reaction much more efficiently than the translational energy ${ }^{115}$. This is understandable according to the barrier locations of the two reactions. The $\mathrm{H}+$ $\mathrm{H}_{2} \mathrm{O} \rightarrow \mathrm{H}_{2}+\mathrm{OH}$ reaction has a late barrier, while the $\mathrm{H}+\mathrm{H}_{2} \mathrm{~S} \rightarrow \mathrm{H}_{2}+\mathrm{SH}$ reaction has an early barrier. As a result, the finding of the mode specific reactivity of the reaction is consistent with the naive extensions of Polanyi rules.

Furthermore, the 6D ISSWP approach was used to investigate the mode specificity of the $\mathrm{H}_{2}+\mathrm{SH} \rightarrow \mathrm{H}+\mathrm{H}_{2} \mathrm{~S}$ reaction ${ }^{147}$. The quantum dynamics calculations revealed that the vibrational excitation of $\mathrm{H}_{2}$ substantially enhances the reactivity and indicates a higher efficacy than translational energy, at least at relatively high energies. In contrast, the vibrational excitation of $\mathrm{SH}$ has a negligible effect on the reaction, indicating the reactant $\mathrm{SH}$ is a good spectator.

\section{7. $\mathrm{OH}+\mathrm{CO} \rightarrow \mathrm{H}+\mathrm{CO}_{2}$}

Because of its crucial role in the conversion of $\mathrm{CO}$ to $\mathrm{CO}_{2}$, the $\mathrm{OH}+\mathrm{CO} \rightarrow$ $\mathrm{H}+\mathrm{CO}_{2}$ reaction is considered as one of the most important reactions in combustion chemistry and atmospheric chemistry. ${ }^{148,} 149$ This exothermic reaction proceeds via two pathways with the formation of a HOCO intermediate complex in trans and cis deep wells. The further decomposition of the HOCO species over significant barriers leads to the production of $\mathrm{CO}_{2}$ and $\mathrm{H}$. It represents a prototype for complex-forming four-atom reactions. ${ }^{25}$

Both kinetic and dynamical measurements, reveal that this reaction proceeds via a complex-forming mechanism on the ground state of the HOCO system. ${ }^{150-153}$ The measured thermal rate constants are nearly independent of temperature under $500 \mathrm{~K}$, but increase steadily with temperature at higher temperatures ${ }^{150,151}$. This strong non-Arrhenius behavior has been attributed to the near-isoenergetic barriers in the entrance $(\mathrm{OH}+\mathrm{CO})$ and exit $\left(\mathrm{H}+\mathrm{CO}_{2}\right)$ channels. The molecular beam experiment 
found the products are scattered in both forward and backward directions, but with a forward bias ${ }^{152,153}$. This indicated that a reasonable HOCO intermediate exists in this reaction, but its lifetime is not very long, supporting the importance of the dynamics.

Theoretically, the $\mathrm{OH}+\mathrm{CO}$ reaction presents a great challenge to both PES construction and quantum dynamics. There are some old PESs for this system ${ }^{154-159}$, but they failed to provide a faithful representation of the complex potential topography. Thus, the previous PESs are not sufficiently accurate for detailed dynamical studies. The situation has been greatly improved, thanks to new PESs based on large numbers of high-level $a b$ initio points and accurate fitting procedures. In 2012, Li et al. developed a global PES ${ }^{160}$ and its modified version ${ }^{161}$ using the PIP fit to roughly $35000 \mathrm{UCCSD}(\mathrm{T})-\mathrm{F} 12 \mathrm{a} / \mathrm{AVTZ}$ data points. In 2013, Chen et al. reported another global $\mathrm{PES}^{12}$ using the $\mathrm{NN}$ method ${ }^{162}$, with data points spreading in a more complete configuration space and computed at essentially the same level of theory. It was found that the NN PES fits the $a b$ initio points much better than the PIP PES. Recently, Li et al. reported a new full-dimensional global PES based on the same $a b$ initio data set generated by Chen et al. ${ }^{163}$. This PES was fit using the PIPNN method ${ }^{13,14}$, which can be considered as the most accurate PES so far for the HOCO system.

Extensive quantum mechanical studies were carried out mainly for the $J=0$ reaction probabilities and rate constants on different PESs 164-166. The reaction probabilities increase with the collision energy, and demonstrate strong oscillatory structures, underscoring the involvement of HOCO resonances. Liu et al. performed full-dimensional ISSWP calculations ${ }^{167}$ on the Lakin - Troya - Schatz - Harding (LTSH) PES ${ }^{158}$ for many $J$ partial waves using the CS approximation. It was found the initial $\mathrm{OH}$ vibrational excitation considerably enhances the reactivity, while initial CO excitation has little effects on the reactivity. The CS approximation was shown to provide reasonably accurate total reaction probabilities for $J>0$. The agreement with experimental rate constants is only qualitative, further underscoring the possible inaccuracies of the LTSH PES. Subsequently, the rate constant calculated on the PIP PES indicated a much better agreement with experiment than that obtained on the 
LTSH PES ${ }^{168}$. The contributions from $J>0$ partial waves were estimated by the $J$-shifting approximation. Furthermore, the rate constants computed using the $J$-shifting approximation on the PIP-NN PES and NN PES are much closer to experimental results than those on the previous PESs ${ }^{163}$, as indicated in Fig. 5. The overall agreement between the results obtained on the two PESs is quite satisfactory, although small differences at low temperatures exist. The rate constant from the PIP-NN PES is slightly closer to experimental results at low temperatures, but the discrepancy between the theoretical and experimental results still remains.

In 2011, the first full-dimensional state-to-state quantum dynamics calculation for total angular momentum $J=0$ on the LTSH PES for $\mathrm{OH}+\mathrm{CO} \rightarrow \mathrm{H}+\mathrm{CO}_{2}{ }^{74,169,170}$ was performed for the ground and vibrationally excited initial states of $\mathrm{OH}$ and $\mathrm{CO}$, using the multi-step RPD method. It was found that the initial CO vibrational excitation essentially has the same effect on the product energy partition as the reagent translational excitation, while the initial $\mathrm{OH}$ excitation leads to slightly more internal energy of $\mathrm{CO}_{2}$. Recently, the full-dimensional state-to-state quantum dynamics calculation for total angular momentum $J=0$ on the most accurate PIP-NN PES was also carried out using the multi-step RPD method. The quantum reaction probabilities for the ground initial rovibrational state on the PIP-NN PES are quite small in magnitude with many narrow and overlapping resonances. As indicated in Fig. 6, the $\mathrm{CO}_{2}$ products are dominantly excited in bending and symmetric modes, but essentially have no excitation in the antisymmetric stretching mode. Quite large population is also seen from the simultaneous excitations of combined bending and symmetric modes. In addition, the validity of the QCT method in describing the dynamics of this reaction was confirmed, except that the QCT calculations ignore important quantum effects, such as tunneling, zero-point energy and resonances.

\section{Five-atom reactions}

1. $\mathrm{H}+\mathrm{NH}_{3} \leftrightarrow \mathrm{H}_{2}+\mathrm{NH}_{2}$

The $\mathrm{H}+\mathrm{NH}_{3} \rightarrow \mathrm{H}_{2}+\mathrm{NH}_{2}$ reaction plays an important role in the chemistry of 
ammonia pyrolysis and combustion at high temperatures. It has become a prototype hydrogen abstraction five-atom reaction, which offers rich dynamics information including mode specificity. A total of nine degrees of freedom should be considered for this reaction and it is extremely challenging to perform an accurate full-dimensional quantum dynamics study without any approximations. Previous quantum treatments for this system mostly applied reduced-dimensional models.

Zhang and coworkers employed a four-dimensional (4D) semirigid vibrating rotor target (SVRT) model $^{171}$, and Yang and Corchado proposed and applied a seven-dimensional (7D) dynamics model ${ }^{172,173}$. In the SVRT approach, the reacting $\mathrm{NH}_{3}$ molecule is treated as semirigid vibrating rotors whose spatial motion is described exactly. In the $7 \mathrm{D}$ model for the $\mathrm{H}+\mathrm{NH}_{3}$ reaction, it was assumed that the nonreactive $\mathrm{NH}_{2}$ group keeps its $C_{2 \mathrm{v}}$ symmetry, the $\mathrm{NH}$ bonds are fixed at their equilibrium values, and the vibration-rotation coupling in the $\mathrm{NH}_{2}$ group is neglected. The same approximations were also used in another 7D model for the quantum dynamics study of the reverse reaction $\mathrm{H}_{2}+\mathrm{NH}_{2}$. These quantum dynamics calculations were performed with an analytic PES originally developed by Corchado and Espinosa-Garcia $(\mathrm{CE})^{174}$.

In 2008, Yang developed a rigorous full-dimensional quantum dynamics method for the reaction between an atom and a tetraatomic molecule ${ }^{175,176}, \mathrm{X}+\mathrm{YABC} \rightarrow$ $\mathrm{XY}+\mathrm{ABC}$. The method was employed to investigate the $\mathrm{H}+\mathrm{NH}_{3} \rightarrow \mathrm{H}_{2}+\mathrm{NH}_{2}$ reaction on improved CE-1997 PES ${ }^{172}$ and also on CE-2010 PES ${ }^{177}$. Due to the relatively low computational power at that time, the relatively small grid/basis was used in that study and the results should not be fully converged. The total reaction probabilities were investigated for the ground vibrational state and four excited vibrational states of ammonia. All the vibrational excitations enhance the reactivity, and the symmetric stretching excitation is more efficient in enhancing reactivity than the asymmetric stretching excitation. The ICSs and rate constants were calculated for the reaction from the ground state with the CS approximation. It was found that the full-dimensional rate constants are larger than the corresponding seven-dimensional values and are overall smaller than those obtained from the variational transition state 
theory.

A new full-dimensional PES based on 103 000 high-level $a b$ initio points was recently developed using the PIP-NN method by Guo and coworkers ${ }^{178}$. The new PIP-NN PES provides a faithful representation of the $a b$ initio points with small root mean squared error (RMSE), and is much more accurate than previous PESs. The dynamics calculations on the PIP-NN PES can provide more trustworthy results and predictions. Very recently, the reaction dynamics and mode specificity of the $\mathrm{H}+\mathrm{NH}_{3}$ reaction were investigated on the PIP-NN PES using the full-dimensional (9D) ISSWP method ${ }^{179}$. It was shown that the symmetric and asymmetric stretching excitations greatly enhance the reactivity, and the efficacies are nearly equivalent, as shown in Fig. 7. The large enhancement can be attributed to their strong couplings with the reaction coordinate at the transition state, according to the SVP model, and their equivalence is apparently due to the local mode nature of the stretching vibration. However, no experimental data is available for comparison, and the equivalence between the symmetric and asymmetric stretching modes of $\mathrm{NH}_{3}$ remains an open question. The results are different from the previous full-dimensional quantum dynamics studies of the same reaction on less accurate PESs, where the symmetric stretching excitation was found to be more effective than the asymmetric stretching excitation. The difference can be attributed to the relatively small grid/basis used in the previous quantum calculations, which might not be sufficient for complete convergence.

A full-dimensional quantum dynamics study of the reverse $\mathrm{H}_{2}+\mathrm{NH}_{2} \rightarrow \mathrm{H}+\mathrm{NH}_{3}$ reaction was first carried out on the accurate PIP-NN PES recently, using the ISSWP method $^{180}$. The ICSs were calculated with the CS approximation or J-shifting approximation, to investigate the reaction dynamics and mode specificity. It was found that vibrational excitation of $\mathrm{H}_{2}$ enhances the reactivity. The excitation of the bending mode of $\mathrm{NH}_{2}$ has negligible effect on the reaction while excitation of either the symmetric or asymmetric stretching mode of $\mathrm{NH}_{2}$ inhibits the reactivity. In addition, all vibrational modes are less effective than translational energy in promoting the reaction. Due to the high computational cost for a full-dimensional 
quantum study for this reaction, a seven-dimensional (7D) quantum model with two non-reactive $\mathrm{NH}$ bonds fixed at their equilibrium geometry was also tested ${ }^{181}$. It was found that the spectator-bond approximation works very well in the energy range studied, while the CS and J-shifting ICSs agree satisfactorily with the coupled-channel results in the low collision energy region, but deviate at the high energies. The ICSs indicated that the rotational excitation of $\mathrm{H}_{2}$ somewhat inhibits the reaction while the rotational excitations of $\mathrm{NH}_{2}$ have little effect.

\section{2. $\mathrm{H}_{2}+\mathrm{C}_{2} \mathrm{H} \rightarrow \mathrm{H}+\mathrm{C}_{2} \mathrm{H}_{2}$}

The ethynyl radial $\left(\mathrm{C}_{2} \mathrm{H}\right)$ plays a key role in the hydrocarbon combustion chemistry ${ }^{182}$. It is one of the most abundant interstellar molecules and has also been detected in planetary atmospheres such as Jupiter and Saturn's satellite Titan ${ }^{183-185}$.

As a full-dimensional quantum dynamics study for this five-atom reaction is rather challenging, reduced-dimensional quantum models were proposed and employed in many calculations. The 7D and 8D quantum models were developed by Wang to investigate the reaction dynamics and mode specificity for the $\mathrm{H}_{2}+\mathrm{C}_{2} \mathrm{H} \rightarrow \mathrm{H}+\mathrm{C}_{2} \mathrm{H}_{2}$ reaction ${ }^{186-188}$. The ICSs were obtained with the CS approximation and $J$-shifting approximations. The reactant $\mathrm{C}_{2} \mathrm{H}$ was approximated as a linear molecule in the $7 \mathrm{D}$ model, and the $\mathrm{C}_{2} \mathrm{H}$ bending mode was included in the 8D model. In 2006, Wang investigated this reaction with a full-dimensional quantum dynamics method, with all 9 degrees of freedom explicitly treated ${ }^{189}$. However, due to the extremely high computational cost, only initial-state selected total reaction probabilities were calculated in that work. Besides, these reduced-dimensional quantum dynamics calculations as well as the full-dimensional study employed an old WB-PES ${ }^{190}$, which was fit using a relatively simple function to limited $a b$ initio data. Sharma et al. developed a new full-dimensional ab initio PIP PES for vinyl radical $\mathrm{HCCH}_{2}$ and the reaction $\mathrm{H}+\mathrm{C}_{2} \mathrm{H}_{2} \rightarrow \mathrm{H}_{2}+\mathrm{C}_{2} \mathrm{H}^{191}$. The large amplitude vibration of $\mathrm{HCCH}_{2}$ and energy transfer in $\mathrm{H}+\mathrm{C}_{2} \mathrm{H}_{2}$ collision were investigated on this PIP PES ${ }^{192,} 193$. Although Wang and coworkers later studied the $\mathrm{H}_{2}+\mathrm{C}_{2} \mathrm{H}$ reaction and its isotopic variants using the 8D quantum model on an improved MWB-PES ${ }^{194-196}$, which 
corrected the barrier height problem on the WB-PES, the dynamical features obtained by a full-dimensional quantum dynamics study on a global accurate $a b$ initio PES are greatly desired.

Very recently, the reaction dynamics and mode specificity of $\mathrm{H}_{2}+\mathrm{C}_{2} \mathrm{H} \rightarrow \mathrm{H}+\mathrm{C}_{2} \mathrm{H}_{2}$ were investigated using the full-dimensional ISSWP method on a new $a b$ initio PES $^{197}$. This PES was constructed using neural network method based on roughly 70 000 data points calculated at UCCSD(T)-F12a/AVTZ level and covers $\mathrm{H}_{2}+\mathrm{C}_{2} \mathrm{H} \leftrightarrow$ $\mathrm{H}+\mathrm{C}_{2} \mathrm{H} 2, \mathrm{H}+\mathrm{C}_{2} \mathrm{H}_{2} \rightarrow \mathrm{HCCH}_{2}$, and $\mathrm{HCCH}_{2}$ radial isomerization reaction regions. The initial-state selected reaction probabilities were calculated for reactants in eight vibrational states, and the corresponding ICSs were calculated with the $J$-shifting approximation. As shown in Fig. 8, the results indicated that the $\mathrm{H}_{2}$ vibrational excitation predominantly enhances the reactivity while the excitation of bending mode of $\mathrm{C}_{2} \mathrm{H}$ slightly inhibits the reaction. The excitations of two stretching modes of $\mathrm{C}_{2} \mathrm{H}$ molecule have negligible effect on the reactivity. The rate constants over 200-2000 K were calculated and agree well with the experimental results. The ICSs indicated that the translational energy has a larger efficacy than vibrational excitations, which is consistent with the predication made by Polanyi rules for an early barrier reaction.

\section{Six-atom reactions}

1. $\mathrm{H}+\mathrm{CH}_{4} \leftrightarrow \mathrm{H}_{2}+\mathrm{CH}_{3}$

The $\mathrm{H}+\mathrm{CH}_{4} \rightarrow \mathrm{H}_{2}+\mathrm{CH}_{3}$ reaction and its reverse are of crucial importance in $\mathrm{CH}_{4} / \mathrm{O}_{2}$ combustion chemistry ${ }^{85}$, and have therefore been extensively studied both experimentally and theoretically ${ }^{198-202}$. It represents a benchmark six-atom reaction to advance our understanding of polyatomic chemical reactivity. Because five atoms involved are hydrogen atoms, it is amenable for high-level $a b$ initio calculations of the PES and quantum dynamics calculations.

It is far from trivial to construct an accurate and efficient full 12-dimensional PES, and substantial efforts have been devoted to constructing accurate PESs for the reaction. The early semiempirical PESs are not considered quantitatively accurate ${ }^{203 \text {, }}$ 
${ }^{204}$, although some $a b$ initio data were used to determine the transition state. In 2004, Manthe and co-workers used the modified Shepard interpolation method ${ }^{5}$ to construct a full-dimensional PES based on high level $a b$ initio calculations ${ }^{205}$. However, this PES is limited to the vicinity of the abstraction reaction barrier, and was used in accurate quantum rate constant calculations, and will not be accurate for global dynamics studies. A global $a b$ initio PES was first developed by Bowman and coworkers using the PIP approach ${ }^{206,207}$. Several versions of the global PES for this system, namely, ZBB1, ZBB2, and ZBB3, including both the abstraction and exchange channels were calculated based on RCCSD(T)/AVTZ data points, which are significantly more accurate than all previous PESs. Later Zhang and coworkers constructed another global PES (ZFWCZ) ${ }^{208}$ using the modified Shepard interpolation method based on UCCSD(T)/AVTZ data points, which has a comparable accuracy to ZBB3 PES. However, the evaluation of the PES is extremely slow due to the nature of the high-dimensional interpolation method. Welsch and Manthe presented the ZFWCZ-WM PES ${ }^{209}$, which is based on the ZFWCZ PES and uses a slightly modified Shepard interpolation scheme extended to the use of modern graphics processing units (GPU). Recently, a new global PES (XCZ) for this system using a neural network fitting method based on UCCSD(T)-F12a/AVTZ data points was calculated by Zhang and co-workers ${ }^{210}$, resulting in a very small total RMSE. The XCZ PES did not enforce the permutational symmetry of five hydrogen atoms explicitly, which can produce accurate results in quantum dynamics calculations but may introduce some errors in QCT calculations. An exchange scheme to solve the problem was proposed, so that the conservation of the total energy can be substantially improved with the exchange scheme in the QCT calculations. Very recently, Li et al. reported a new full-dimensional global PES (LCZXZG) ${ }^{211}$ for the reactive system based on the original $a b$ initio data points and also additional more data points computed at the same level used in the XCZ PES, employing the PIP-NN fitting method. This PES uses a set of PIPs instead of pairwise distances as input data in the neural network and guarantees the correct permutational symmetry, but results in a bit higher RMSE than the XCZ PES. 
An eight-dimensional (8D) model has been employed to perform time-dependent ISSWP studies of the $\mathrm{H}+\mathrm{CH}_{4} \leftrightarrow \mathrm{H}_{2}+\mathrm{CH}_{3}$ reaction and its isotope analogies ${ }^{212,213}$. This model was originally proposed by Palma and Clary ${ }^{214}$, in which the nonreacting $\mathrm{CH}_{3}$ group was restricted in a $\mathrm{C}_{3 \mathrm{v}}$ symmetry during the reaction. Since the assumption holds very well in reality, the model has a quantitative level of accuracy. Furthermore, the $\mathrm{CH}$ bond lengths in the nonreacting $\mathrm{CH}_{3}$ group can be fixed, and thus the number of degrees of freedom was reduced to seven ${ }^{212}$. In 2010, Zhang and coworkers employed the seven-dimensional (7D) quantum model to perform the ISSWP calculations for the $\mathrm{H}+\mathrm{CD}_{4} \rightarrow \mathrm{HD}+\mathrm{CD}_{3}$ reaction on both the ZFWCZ and ZBB2 PESs, where good agreement was achieved between theory and experiment on the energy dependence of the ICS in a wide collision energy region ${ }^{45}$. The effects of the $\mathrm{CHD}_{3}$ vibrational excitation for the $\mathrm{H}+\mathrm{CHD}_{3} \rightarrow \mathrm{H}_{2}+\mathrm{CD}_{3}$ reaction were also investigated using the 7D ISSWP method on the ZFWCZ PES, which revealed that the $\mathrm{C}-\mathrm{H}$ stretching excitation can promote the reaction dramatically ${ }^{215}$. Besides, a six-dimensional (6D) state-to-state quantum dynamics study of the $\mathrm{H}+\mathrm{CH}_{4} \rightarrow$ $\mathrm{H}_{2}+\mathrm{CH}_{3}$ reaction was carried out using the RPD scheme on the XCZ PES ${ }^{216}$, which was based on the 7D model by assuming that the $\mathrm{CH}_{3}$ group can rotate freely with respect to its $\mathrm{C}_{3 \mathrm{v}}$ symmetry axis. The calculation indicated that the $6 \mathrm{D}$ treatment can produce essentially the same reaction probabilities as the 7D results. The product vibrational/rotational state distributions and product energy partitioning information were obtained for ground initial rovibrational state with the total angular momentum $J$ $=0$. The first coupled channel (CC) calculation for the $\mathrm{H}+\mathrm{CHD}_{3} \rightarrow \mathrm{H}_{2}+\mathrm{CD}_{3}$ reaction using the 7D model was performed on the XCZ PES ${ }^{217,218}$. It was found that the centrifugal sudden (CS) approximation considerably underestimated the CC results, and the initial rotational excitation of $\mathrm{CHD}_{3}$ up to $J_{0}=2$ does not have any effect on the total cross sections. Transition state wave packet calculations were also carried out $^{219,220}$ with all the eight DOF for the $\mathrm{C}_{3 \mathrm{v}}$ model included by using the original Hamiltonian proposed by Palma and Clary ${ }^{214}$. In 2012, Yang and coworkers proposed a new 8D quantum mechanical Hamiltonian ${ }^{47}$ based on Palma and Clary's model. The new Hamiltonian is in a simple form and easy to implement, and has become the 
choice of $8 \mathrm{D}$ quantum scattering calculations for the $\mathrm{X}+\mathrm{CYZ}_{3}$ type of reactions.

Very recently, a 8D quantum dynamical approach based on Palma and Clary's model was proposed for the $\mathrm{H}_{2}+\mathrm{CH}_{3} \rightarrow \mathrm{H}+\mathrm{CH}_{4}$ reaction ${ }^{221}$,222, which is similar to that for its reverse reaction $\mathrm{H}+\mathrm{CH}_{4} \rightarrow \mathrm{H}_{2}+\mathrm{CH}_{3}$. Total reaction probabilities and ICSs were calculated for the ground and a number of vibrationally excited initial states to investigate the effects of vibrational excitations of both reagents on the reaction. The results indicated that the $\mathrm{CH}$ stretching excitation has a negligible effect on the reaction and the 7D model with the $\mathrm{CH}$ bond length fixed works very well for the reaction, as shown in Fig. 9. The $\mathrm{H}_{2}$ stretching and $\mathrm{CH}_{3}$ umbrella modes, along with the translational energy, strongly promote the reactivity. The mode specificity can be interpreted by the recently proposed sudden vector projection model, which attributes the enhancement effects of the reactant modes to their strong couplings with the reaction coordinate at the transition state. The calculated rate constants were found to be in good agreement with available experimental measurements and other theoretical results.

Manthe and coworkers have been developing an efficient full-dimensional quantum dynamical scheme to investigate reactions such as $\mathrm{H}+\mathrm{CH}_{4} \rightarrow \mathrm{H}_{2}+\mathrm{CH}_{3}$. In recent years, full-dimensional quantum dynamics calculations could investigate initial state-selected reaction probabilities ${ }^{223-228}$ and state-to-state reaction probabilities ${ }^{49}, 229$ for total angular momentum $J=0$ for this benchmark six-atom reaction. These calculations employed the TSWP approach, which is based on the quantum transition state concept based on flux correlations functions, to efficiently describe the reaction process. The wave packet propagation was carried out using the multilayer MCTDH approach. It was found that the stretching excitation and also umbrella excitation promote the $\mathrm{H}+\mathrm{CH}_{4} \rightarrow \mathrm{H}_{2}+\mathrm{CH}_{3}$ reaction, but the rotational excitation inhibits the reactivity. The magnitude of this effect strongly depends on the initial vibrational state. The contributions of the vibrational states of the activated complex to the reactivity was analyzed in detail. They also reported the first full-dimensional $(J=0)$ calculation of state-to-state reaction probabilities for the $\mathrm{H}+\mathrm{CH}_{4} \rightarrow \mathrm{H}_{2}+\mathrm{CH}_{3}$ reaction for various initial vibrational and rotational states of $\mathrm{CH}_{4}{ }^{49}$. It was found that the 
vibrational state distributions of the products are essentially independent of the initial rovibrational state of the reactants, in which only vibrational excitation in the methyl umbrella mode was observed, but no excitation in $\mathrm{H}_{2}$ vibration or another $\mathrm{CH}_{3}$ vibration was seen (see Fig. 10). The observed loss of vibrational memory can be explained by the quantum transition-state concept.

\section{2. $\mathrm{H}^{\prime}+\mathrm{CH}_{4} \rightarrow \mathrm{H}+\mathrm{CH}^{\prime} \mathrm{H}_{3}$}

In addition to the $\mathrm{H}+\mathrm{CH}_{4} \rightarrow \mathrm{H}_{2}+\mathrm{CH}_{3}$ abstraction reaction, there exists a substitution reaction, $\mathrm{H}^{\prime}+\mathrm{CH}_{4} \rightarrow \mathrm{H}+\mathrm{CH}^{\prime} \mathrm{H}_{3}$, with a $\mathrm{D}_{3 h}$ transition state and a static barrier height of $1.6 \mathrm{eV}$. It is the simplest reaction proceeding through the back-side attack Walden inversion mechanism, very similar to the gas-phase $S_{N} 2$ reactions with central barriers, except that the $\mathrm{S}_{\mathrm{N}} 2$ reactions have pre- and post-reaction wells arising from strong ion-dipole interaction between reagents and products. Very recently, Zhang and coworkers reported an accurate quantum dynamics study of the $\mathrm{H}+\mathrm{CH}_{4}$ substitution reaction and its isotope analogues, employing the above 7D quantum model on the accurate $a b$ initio LCZXZG PES ${ }^{50}$. The calculations reveal that the reaction exhibits a strong normal secondary isotope effect on the ICSs measured above the reaction threshold, and a small but reverse secondary kinetic isotope effect at room temperature, as shown in Fig. 11. The reaction proceeds along a path with a considerably higher barrier height than the static barrier, as the umbrella angle of the non-reacting $\mathrm{CH}_{3}$ group cannot change synchronously with the other reaction coordinates during the reaction owing to insufficient energy transfer from the translational motion to the umbrella mode. Those investigations provided unprecedented dynamical details for this simplest Walden inversion reaction, and also shed valuable light on the dynamics of gas-phase $\mathrm{S}_{\mathrm{N}} 2$ reactions.

\section{3. $\mathrm{F}+\mathrm{CH}_{4} \rightarrow \mathrm{HF}+\mathrm{CH}_{3}$}

The $\mathrm{F}+\mathrm{CH}_{4} \rightarrow \mathrm{HF}+\mathrm{CH}_{3}$ reaction plays an important role in the atmosphere and stratosphere, and it has become a prototype for understanding the mode specificity 
and bond selectivity in polyatomic bimolecular reactions. This reaction has a very low reactant-like barrier of roughly $0.8 \mathrm{kcal} / \mathrm{mol}$, and a shallow van der Waals (vdW) well in the entrance channel. It is very exothermic and there is a relatively deep vdW minimum in the product valley.

Many experimental and theoretical studies were performed to investigate the reaction dynamics of this reaction. Recent crossed molecular beam studies carried out by Liu and Yang groups revealed the similar influences of C-H vibrational excitation on the reactivity of the $\mathrm{F}+\mathrm{CHD}_{3}$ reaction ${ }^{230-232}$. Liu and coworkers observed that the excitation of the $\mathrm{C}-\mathrm{H}$ vibration significantly reduces the overall reactivity at low collisions energies, and the reaction with the vibrationally excited $\mathrm{CHD}_{3}$ favors the $\mathrm{DF}+\mathrm{CHD}_{2}$ channel at the expense of the $\mathrm{HF}+\mathrm{CD}_{3}$ channel $^{230}$. The reduction of reactivity was also reported by Yang and coworkers at a higher collision energy ${ }^{231,232 .}$ However, the QCT calculations on global $a b$ initio PESs failed to reproduce the experimental observations on the influence of the $\mathrm{C}-\mathrm{H}$ vibration excitation on the reactivity. It was found in recent QCT studies that the $\mathrm{C}-\mathrm{H}$ vibrational excitation enhances the overall reactivity by Czakó et al. and Palma et al. on two PESs ${ }^{233-237}$. The discrepancy between experiment and theory might result from the classical model used for describing the dynamics, which neglects quantum effects. Therefore, an accurate full quantum characterization of this reaction is highly desirable in view of potentially important quantum effects, such as tunneling, zero-point energy (ZPE) and resonances.

Due to the vdW well in the entrance channel of the $\mathrm{F}+\mathrm{CH}_{4}$ reaction, the reaction dynamics can be strongly influenced by the resonances, which requires very long propagation time in the time-dependent quantum dynamics calculations. In particular, the reaction probabilities are difficult to converge at low collision energies. Earlier quantum dynamics studies were restricted to low-dimensional quantum models, which included a maximum of five degrees of freedom ${ }^{238-241}$.

Recently, the mode specific reactivity of the $\mathrm{F}+\mathrm{CHD}_{3} \rightarrow \mathrm{HF}+\mathrm{CD}_{3}$ reaction was investigated using an 8D quantum dynamical approach ${ }^{242}$, which was based on the model proposed by Palma and Clary ${ }^{214}$. A recently developed $a b$ initio based 
full-dimensional PES considering the spin-orbit coupling by Palma, Westermann, Eisfeld, and Manthe (PWEM-SO) 236, 237 was employed. This PES provides a more accurate description of the reactant channel than the Czakó, Shepler, Braams, and Bowman (CSBB) $\mathrm{PES}^{235}$. In the transition-state and product region, the PWEM-SO PES is smoothly switched to the CSBB PES. The reaction probabilities with the total angular $J=0$ and ICSs with the $J$-shifting approximation from different vibrational states were calculated. The obtained results demonstrate dominant resonance structures at low collision energies and absence of an energy threshold in reaction probabilities. It was found that the excitation of the $\mathrm{C}-\mathrm{H}$ vibration in $\mathrm{CHD}_{3}$ significantly increase the reactivity, which disagrees with the available experimental data, as shown in Fig. 12. While the excitation of the C-D stretching or $\mathrm{CD}_{3}$ umbrella mode has a relatively small impact on the reactivity. Possible sources of this disagreement were discussed both from experimental and theoretical sides. Further investigations are still necessary both experimentally and theoretically, which can resolve the discrepancy in future.

\section{4. $\mathrm{Cl}+\mathrm{CH}_{4} \rightarrow \mathrm{HCl}+\mathrm{CH}_{3}$}

Due to its importance in atmospheric chemistry, the $\mathrm{Cl}+\mathrm{CH}_{4}$ reaction has been the subject of numerous experimental and theoretical investigations. The $\mathrm{Cl}+\mathrm{CH}_{4} \rightarrow$ $\mathrm{HCl}+\mathrm{CH}_{3}$ reaction has a product-like barrier (later barrier), and thus according to the extended Polanyi rules, the vibrational excitation is supposed to be more efficient than the translational motion in promoting the reaction.

Surprisingly, crossed molecular beam experiments carried out by Liu and coworkers for the $\mathrm{Cl}+\mathrm{CHD}_{3}$ reaction observed that the ICS for the $\mathrm{CD}_{3}(v=0)$ product for the initial $\mathrm{CH}$ stretch excited state is smaller than that at low translational energies and becomes comparable at higher translational energies to the corresponding one for the ground initial state 243,244 . Based on their estimation that most of $\mathrm{CD}_{3}$ product resulting in the ground vibrational state $(v=0)$, they revealed that the stretch excitation is no more effective or slightly more effective in promoting the late-barrier $\mathrm{Cl}+\mathrm{CHD}_{3}$ reaction than an equivalent amount of translational energy, which is inconsistent with 
the Polanyi rules.

In 2012, Zhang and coworkers performed a 7D quantum dynamics study based on the Palma-Clary model for the $\mathrm{Cl}+\mathrm{CHD}_{3}$ reaction to investigate the vibrational excitation effect on the reactivity ${ }^{46}$. A high-quality, full-dimensional global PES developed by Czakó and Bowman (CB PES) $)^{245,246}$ for the reactive system based on accurate $a b$ initio calculations was employed in the quantum dynamics calculations. The ICSs for different vibrational states were obtained based on the CS approximation on calculating the reaction probabilities for $J>0$. The quantum dynamics results revealed that the vibrational enhancement by the $\mathrm{C}-\mathrm{H}$ stretch excitation is actually very significant, except at very low collision energies, as indicated in Fig. 13. After a careful reexamination of the experimental data, it was revealed that the discrepancy between the original experimental data and 7D quantum dynamical results arises from the incompleteness of the measurement ${ }^{247}$. By including more rotational states of product, they found the $\mathrm{CH}$ stretch excitation becomes more efficacious than the same amount of translational energy in promoting the reaction, which agrees reasonably well with the 7D quantum dynamics calculation. A later 7D quantum dynamics study by Yang and coworkers also investigated the rotational mode specificity of the $\mathrm{Cl}+\mathrm{CHD}_{3}$ reaction ${ }^{248}$, which reproduced the experimental results that the low-lying rotational states of $\mathrm{CHD}_{3}$ are more reactive than its rotationless counterpart.

Recently, an 8D quantum dynamics study for the $\mathrm{Cl}+\mathrm{CH}_{4} \rightarrow \mathrm{HCl}+\mathrm{CH}_{3}$ reaction was carried out on the CB PES ${ }^{249}$. The reaction probabilities for the reactant $\mathrm{CH}_{4}$ initially in its ground vibrational state and low-lying excited states were calculated, and the ICSs were obtained with the $J$-shifting approximation. All vibrational excitations considered enhance the reaction significantly, with the largest enhancement from the excitation of the stretching modes, indicating that the Polanyi rules hold well in this late-barrier polyatomic reaction, except for low collision energies. The thermal rate constant is in good agreement with the experimental results, in particular in the low temperature region.

Experimental studies ${ }^{250,251}$ showed that the spin-orbit state $\mathrm{Cl}\left({ }^{2} \mathrm{P}_{1 / 2}\right)$ also plays a small but important contribution to the reaction. Nonadiabatic effects in triatomic 
reactions have been well studied ${ }^{30,252}$. However, multiple-surface quantum scattering calculations on polyatomic reactions involving radicals such as $\mathrm{Cl}, \mathrm{F}, \mathrm{Br}, \mathrm{O}$ and $\mathrm{OH}$ remain a challenge due to the computational cost in constructing PESs with multiple electronic states. Recently, Remmert et al. ${ }^{253}$ developed a method to study this type of systems based on reduced-dimensionality (RD) approximation. It has been applied to study both the $\mathrm{Cl}\left({ }^{2} \mathrm{P}_{\mathrm{J}}\right)+\mathrm{CH}_{4} \rightarrow \mathrm{HCl}+\mathrm{CH}_{3}{ }^{253}$ and $\mathrm{Cl}\left({ }^{2} \mathrm{P}_{\mathrm{J}}\right)+\mathrm{CHD}_{3} \rightarrow \mathrm{HCl}+\mathrm{CD}_{3}{ }^{254}$ reactions in selected spin-orbit states. The calculated rate constants and ICSs showed very good agreement to the experimental results.

\section{5. $\mathrm{O}\left({ }^{3} \mathrm{P}\right)+\mathrm{CH}_{4} \rightarrow \mathrm{OH}+\mathrm{CH}_{3}$}

The $\mathrm{O}\left({ }^{3} \mathrm{P}\right)+\mathrm{CH}_{4} \rightarrow \mathrm{OH}+\mathrm{CH}_{3}$ reaction plays an important role in hydrocarbon combustion $^{255}$. It has a more-or-less central barrier, which is neither reactant-like nor product-like. Extensive experimental and theoretical studies have been carried out for this prototype of central-barrier reaction. Recent crossed molecular beam experiments have obtained the excitation function, mode specific reactivity, internal state distributions of both the $\mathrm{CH}_{3}$ and $\mathrm{OH}$ product and DCSs for this reactive system ${ }^{256-259}$. It was found the excitation of the $\mathrm{C}-\mathrm{H}$ vibration in $\mathrm{CHD}_{3}$ for the $\mathrm{O}\left({ }^{3} \mathrm{P}\right)+\mathrm{CHD}_{3}$ reaction significantly enhanced the reactivity for the $\mathrm{OH}+\mathrm{CD}_{3}$ channel. However, the bending excitations in $\mathrm{CD}_{4}$ slightly inhibit the $\mathrm{O}\left({ }^{3} \mathrm{P}\right)+\mathrm{CD}_{4}$ reaction.

The theoretical studies were almost based on the $\mathrm{QCT}^{260,} 261$ and reduced-dimensional quantum dynamics ${ }^{262-265}$ calculations. Recently, an 8D ISSWP study based on the Palma-Clary model was performed for the $\mathrm{O}\left({ }^{3} \mathrm{P}\right)+\mathrm{CH}_{4} \rightarrow$ $\mathrm{OH}+\mathrm{CH}_{3}$ reaction ${ }^{48}$, using an $a b$ initio full-dimensional global PES recently developed with the PIP method by Czakó and Bowman ${ }^{266}$. This 8D model includes representatives of all $\mathrm{CH}_{4}$ vibrational modes, particularly the asymmetric stretching mode ignored in the 7D model ${ }^{213}$. The calculated ICS for $\mathrm{CH}_{4}$ initially in the ground state agrees well with the experimental measurement. It was found that the translational energy is more efficient in promoting the reaction than the vibrational excitations. The excitations in the stretching modes of $\mathrm{CH}_{4}$ significantly enhance the reaction, with the symmetric stretch having a higher efficacy and the excitations in the 
bending and umbrella modes having a smaller impact, as shown in Fig. 14.

\section{Seven-atom reactions}

1. $\mathrm{OH}+\mathrm{CH}_{4} \rightarrow \mathrm{H}_{2} \mathrm{O}+\mathrm{CH}_{3}$

The $\mathrm{OH}+\mathrm{CH}_{4} \rightarrow \mathrm{H}_{2} \mathrm{O}+\mathrm{CH}_{3}$ reaction is a key step in the combustion of hydrocarbon fuels ${ }^{267}$. It also represents the major mechanism for the removal of the greenhouse gas methane in the troposphere ${ }^{268}$. Experimental rate coefficients for the reaction have been measured over a wide range of temperatures ${ }^{269}$. Crossed molecular beam experiments were carried out to study the state-to-state dynamics for the $\mathrm{OH}+\mathrm{CD}_{4}$ reaction by Liu and coworkers ${ }^{270-272}$. The early quantum dynamics calculations were restricted to two-three degrees of freedom ${ }^{273,274}$, and then more degrees of freedom up to seven ${ }^{275-277}$ were included to investigate the reaction dynamics, partly due to the emergence of accurate global PESs. The first global PES was constructed by Espinosa-García and Corchado based on an analytical function (PES-2000) $)^{278}$, which was further refined by them (PES-2014).

Recently, six-dimensional (6D) and seven-dimensional (7D) ISSWP calculations were performed on the PES-2000276, 277. The 6D and 7D Hamiltonians were mainly based on the Palma-Clary model, which restricted the nonreactive $\mathrm{CH}_{3}$ group in the $\mathrm{C}_{3 v}$ symmetry $^{214}$. Further simplification includes the removal of the internal rotation of $\mathrm{CH}_{3}$ and freezing of the $\mathrm{C}-\mathrm{H}$ bond, which results in the 7D model. The 7D model can be further simplified by fixing the $\mathrm{OH}$ bond length, leading to the $6 \mathrm{D}$ model. The reaction probabilities and ICSs from ground and several excited vibrational states of $\mathrm{CH}_{4}$ were calculated with the $\mathrm{CS} / J$-shifting and without the CS approximations. The $\mathrm{OH}$ radical can be treated well as a spectator because it has a negligible effect on the reaction. Excitations of the $\mathrm{C}-\mathrm{H}$ stretch and/or the $\mathrm{CH}_{3}$ umbrella mode enhance the reaction, although they are less efficient than the translational energy in promoting the reaction, at least at low collision energies, consistent with the extended Polanyi rules for this early barrier reaction. It was found that the CS approximation works well in the entire energy region considered, but the $J$-shifting approximation only 
produces accurate results at low collision energies. In addition, the $6 \mathrm{D}$ results indicated that the rotational excitation of $\mathrm{CH}_{4}$ has little influence on the reactivity, but the rotational excitation of $\mathrm{OH}$ inhibits the reactivity slightly.

Since the PES-2000 and PES-2014 were calculated based on a simple functional form, the dynamical uncertainties result from the two PESs remain unclear. Very recently, Li and Guo developed a new global full-dimensional PES using the PIP-NN approach based on large number of high-level $a b$ initio points ${ }^{279}$. This PES is considered globally accurate based on the small RMS fitting error and preliminary QCT results. Using this PES, Song et al. investigated the mode specific reactivity for the $\mathrm{OH}+\mathrm{CHD}_{3}$ reaction by the 6D ISSWP and QCT approaches ${ }^{280}$. The quantum dynamical results indicated that the excitation of $\mathrm{CH}$ stretch promotes the reaction, while the excitation of umbrella mode of $\mathrm{CHD}_{3}$ has a negligible effect on the reaction. It is interesting that the translational energy is more efficient than the $\mathrm{CH}$ stretching mode in promoting the reaction, except at very high collision energies, which were reproduced by QCT calculations (see Fig. 15). This finding is consistent with the extended Polanyi rules for this polyatomic reaction with an early barrier.

\section{2. $\mathrm{F}+\mathrm{CH}_{3} \mathrm{OH} \rightarrow \mathrm{HF}+\mathrm{CH}_{3} \mathrm{O}$}

The seven-atom $\mathrm{F}+\mathrm{CH}_{3} \mathrm{OH} \rightarrow \mathrm{HF}+\mathrm{CH}_{3} \mathrm{O}$ reaction was recently investigated by a joint high-resolution photoelectron imaging and theoretical quantum dynamics study ${ }^{281}$, based on the photodetachment of the stable $\mathrm{CH}_{3} \mathrm{OHF}^{-}$anion. The measurements reveal spectral features associated with a manifold of vibrational Feshbach resonances and bound states supported by the post-transition state potential well. To simulate the photoelectron spectrum, wave-packet-based quantum dynamics was investigated with a reduced 6D model by freezing the methyl moiety, based on a global PIP-NN PES obatined by fitting a large number of UCCSD(T)-F12a/AVDZ points in full dimensionality. The remaining six coordinates were represented by the diatom-diatom Jacobi coordinates. The photodetachment process was simulated within the Condon approximation, where the anion wavefunction was placed on the neutral PES in a vertical transition. The subsequent dynamics calculations were 
followed by propagating the initial wave packet in the Chebyshev order domain and the photoelectron spectrum was computed by a discrete cosine transform of the Chebyshev autocorrelation function. The experimental spectrum was assigned with the help of $6 \mathrm{D}$ quantum dynamics calculations, and the resonances were fully reproduced by theory, which demonstrate that the key dynamics of this seven-atom bimolecular reaction can be captured with a relatively simple physical picture.

\section{Reactions beyond six-atoms with approximate methods}

For chemical reactions involving more than six atoms quantum dynamical calculations currently require some approximations due to the large number of degrees of freedom involved. Furthermore the lack of suitable PESs has meant the number of published quantum dynamical studies for these bimolecular reactions in the gas phase has been small. Approximate quantum dynamical calculations that have been published in the last ten years on reactions with more than six atoms are discussed in this section.

\section{Reduced dimensionality method}

A practical approach is the so-called RD method, ${ }^{282,}{ }^{283}$ in which a RD PES is constructed instead of a FD PES. It is based on the idea that in systems consisting of large molecules, some of the atoms in each molecule are far away from the reaction centre, and hence the vibrational motions involving these atoms contribute significantly less than the atoms that are close to the reaction centre. In such an approach, the internal degrees of freedom (DoFs) of the system are divided into two groups: active modes and spectator modes. ${ }^{253,254,284-292}$ The PES is then constructed according to variations of the active mode coordinates, while the contribution of the spectator modes to the reaction are included as zero-point energies (ZPE). For instance, one commonly used 2D model 253 , 254, 284-286, 288-290, 292 treats two bond lengths that correspond to the chemical bonds formed and broken in a reaction 
as the active modes. Recently this method has been applied to larger systems, in particular the $\mathrm{H}$-atom abstraction or exchange reactions, such as $\mathrm{H}+\mathrm{CH}_{3} \mathrm{NH}_{2} \rightarrow$ $\mathrm{H}_{2}+\mathrm{CH}_{3} \mathrm{NH} / \mathrm{CH}_{2} \mathrm{NH}_{2}{ }^{288}, \mathrm{H}+\mathrm{CH}_{4} \rightarrow \mathrm{H}_{2}+\mathrm{CH}_{3}{ }^{284,}{ }^{285}, \mathrm{CH}_{3}+\mathrm{CH}_{4} \rightarrow \mathrm{CH}_{4}+\mathrm{CH}_{3}{ }^{285,286}$, $\mathrm{Cl}+\mathrm{CH}_{4} / \mathrm{CHD}_{3} \rightarrow \mathrm{HCl}+\mathrm{CH}_{3} / \mathrm{CD}_{3}{ }^{253,}{ }^{254}, \mathrm{H}+\mathrm{C}_{2} \mathrm{H}_{6} \rightarrow \mathrm{H}_{2}+\mathrm{C}_{2} \mathrm{H}_{5}{ }^{287}, \mathrm{H}+\mathrm{C}_{3} \mathrm{H}_{8} \rightarrow$ $\mathrm{H}_{2}+\mathrm{n}-\mathrm{C}_{3} \mathrm{H}_{7} / \mathrm{i}-\mathrm{C}_{3} \mathrm{H}_{7}{ }^{287}, \quad \mathrm{H}+\mathrm{n}-\mathrm{C}_{4} \mathrm{H}_{10} \rightarrow \mathrm{H}_{2}+1-\mathrm{C}_{4} \mathrm{H}_{9} / 2-\mathrm{C}_{4} \mathrm{H}_{9}{ }^{291}, \quad \mathrm{H}+\mathrm{HCF}_{3} \rightarrow$ $\mathrm{H}_{2}+\mathrm{CF}_{3}{ }^{293}, \mathrm{H}+$ сус- $\mathrm{C}_{3} \mathrm{H}_{6} \rightarrow \mathrm{H}_{2}+$ сус- $\mathrm{C}_{3} \mathrm{H}_{5}{ }^{292}, \mathrm{H}+\mathrm{Si}\left(\mathrm{CH}_{3}\right)_{4} \rightarrow \mathrm{H}_{2}+\mathrm{Si}\left(\mathrm{CH}_{3}\right)_{3} \mathrm{CH}_{2}{ }^{289}$, $\mathrm{H}+\mathrm{H}_{2} \mathrm{CO} \rightarrow \mathrm{H}_{2}+\mathrm{HCO}^{290}$, and $\mathrm{Cl}^{-}+\mathrm{CH}_{3} \mathrm{Br} \rightarrow \mathrm{Br}^{-}+\mathrm{CH}_{3} \mathrm{Cl}^{294}$.

One approach to construct the RD PES has used quantum chemistry methods of reasonable accuracy to compute the zero-point energies of the spectator modes while using highly accurate quantum chemistry to calculate the points on the 2D PES in the bonds being broken and formed. In this way the effective barrier height at the transition state and energetics for the reactants and products are accurate, which is crucial for reaction dynamics and kinetics. ${ }^{295-297}$

A good example of this approach is the direct $\mathrm{H}$-abstraction from the methylamine $\left(\mathrm{CH}_{3} \mathrm{NH}_{2}\right)$ molecule by an $\mathrm{H}$ atom which plays an important role in atmospheric processes. Two possible reaction routes can take place resulting in either $\mathrm{CH}_{2} \mathrm{NH}_{2}$ or $\mathrm{CH}_{3} \mathrm{NH}$ radicals. The methylamine molecule $\left(\mathrm{CH}_{3} \mathrm{NH}_{2}\right)$ itself has 15 DoFs including internal rotation and inversion motions. Kerkeni et al. ${ }^{288}$ constructed a 2D PES for each reaction channel with the $\mathrm{H}-\mathrm{H}$ and the $\mathrm{H}-\mathrm{C}$ or $\mathrm{H}-\mathrm{N}$ bond lengths as the coordinates. A rectilinear coordinate projection method, was used to project out the contribution of the active modes from the spectator modes and the post-projection spectator mode ZPE was added to the single point $a b$ initio energy to calculate the PES. The 2D nuclear Schrödinger equation was solved with the R-matrix propagation method in combination with the $J$-shifting model. ${ }^{283,295}$ The resulting rate constants had very good agreement to the experimental data and also showed clear contribution of the quantum tunneling effect to the reaction. A similar procedure has been recently applied to the study of $\mathrm{H}+\mathrm{H}_{2} \mathrm{CO} \rightarrow \mathrm{H}_{2}+\mathrm{HCO}^{290}$ and $\mathrm{H}+\mathrm{Si}\left(\mathrm{CH}_{3}\right)_{4} \rightarrow$ $\mathrm{H}_{2}+\mathrm{Si}\left(\mathrm{CH}_{3}\right)_{3} \mathrm{CH}_{2}{ }^{289}$ reactions.

This projection of the Hessian matrix in rectilinear coordinates has been used in the RD PES constructions recently due to its simplicity. However, the 
post-projection frequencies at non-globally optimized geometries in the rectilinear coordinate representation may have imaginary values, which are not physically meaningful. Banks et al. ${ }^{284}$ proposed the use of a projection method in curvilinear coordinates to remove this difficulty and applied it to the RD study of the $\mathrm{H}+\mathrm{CH}_{4}$ reaction. The method of calculating the projection operator in the curvilinear coordinates was later simplified. ${ }^{285}$ This method was tested on various chemical reactions, including $\mathrm{CH}_{3}+\mathrm{CH}_{4}{ }^{285}$ and $\mathrm{H}+\mathrm{CH}_{4} / \mathrm{C}_{2} \mathrm{H}_{6} / \mathrm{C}_{3} \mathrm{H}_{8}{ }^{287}$. In addition, better description of some of the vibrational modes, such as linear bending, can be achieved $^{284}$. The curvilinear corrected ZPE, as expected, has different values from the rectilinear corrected ZPE. This affects the RD PES. Examples of the differences in ZPE between curvilinear and rectilinear methods across the grid points for several reactions were reported. ${ }^{285}$ The curvilinear corrected PES in the reactant and product asymptotes are generally lower in energy than the equivalent eigenstate for the rectilinear corrected PES. Thus the curvilinear corrected RD PES produces a larger reaction barrier and less tunneling than the rectilinear counterparts. However, the resulting rate constant has a significantly better fit to experimental data. ${ }^{253,285,287}$

In the studies of chemical reactions involving large molecules, the reaction rate constant attracts the most experimental interest. Recently, von Horsten et al. ${ }^{287}$ developed a $(1+1) \mathrm{D}$ model to construct an approximate 2D PES that provides a good rate constant estimation and saves a noticeable amount of computational cost. In the $(1+1) \mathrm{D}$ model, one calculates the 2D minimum energy path (MEP) of a reaction with the $2 \mathrm{D}$ corresponding to the chemical bonds being formed and broken in the reaction and performs the vibrational mode projection in the curvilinear coordinates. This spectator mode ZPE corrected MEP is referred to as the $1 \mathrm{D}$. The remaining areas on a normal 2D PES are determined by harmonic expansion in curvilinear coordinates about each point along the MEP. This method is similar in spirit to the reaction path Hamiltonian model by Miller et $a .^{298}$ or the harmonic adiabatic approximation by Lauvergnat et al. ${ }^{299}$ However, the similarity is only limited in the 2D PES construction, the nuclear motion Schrödinger equation for the two DoFs is solved using quantum scattering calculation. The advantage of this method is the reduction of 
computational cost for a PES construction. Typically, only $\sim 60 a b$ initio grid points are required in a $(1+1) \mathrm{D}$ calculation, ${ }^{287}$ while the construction of a $2 \mathrm{D}$ PES requires over 100 grid points. A simplified (1+1)D model based on 1D Morse potential fitting was proposed and tested on the $\mathrm{H}+\mathrm{n}-\mathrm{C}_{4} \mathrm{H}_{10} \rightarrow \mathrm{H}+1-\mathrm{C}_{4} \mathrm{H}_{9} / 2-\mathrm{C}_{4} \mathrm{H}_{9}{ }^{291}$ and $\mathrm{H} / \mathrm{D}+\mathrm{HCF}_{3} / \mathrm{DCF}_{3} \leftrightarrow \mathrm{H}_{2} / \mathrm{D}_{2}+\mathrm{CF}_{3}{ }^{293}$ reactions.

The tests of this $(1+1) \mathrm{D}$ method were carried out on several H-abstraction reactions from hydrocarbon molecules and the resulting reaction rate constants showed very good agreement with other theoretical works and experimental data. ${ }^{287}$, 291, 293 The cumulative reaction probability of the (1+1)D calculation shows good agreement to the $2 \mathrm{D}$ results at low collision energies. ${ }^{287}$ The disadvantage of the $(1+1) \mathrm{D}$ method is that it requires certain geometries of the grid points on the MEP. In particular, the three atoms involved in the formation and breaking of chemical bonds are assumed to be in a collinear or near-collinear configuration. Systems with van der Waals (vdW) complexes that breaks this geometrical arrangement, therefore, cannot be represented in this model. An example is the $\mathrm{H}+$ cyc- $\mathrm{C}_{3} \mathrm{H}_{6} \rightarrow \mathrm{H}_{2}+$ cyc- $\mathrm{C}_{3} \mathrm{H}_{5}$ reaction reported by Shan et al. ${ }^{292}$ where the reactants forms a vdW complex with the H-atom sitting on top of the cyc- $\mathrm{C}_{3} \mathrm{H}_{6}$ ring. Shown in Fig. 16(a), with a carefully chosen set of internal coordinates, one can easily include both stationary structures in a fitted 2D PES. The resulting QRS rate constant in Fig. 16(b) shows very good agreement to experimental data ${ }^{300,301}$.

More recently, Hennig and Schmatz ${ }^{294}$ reported a RD quantum scattering calculation on the $\mathrm{Cl}^{-}+\mathrm{CH}_{3} \mathrm{Br} \rightarrow \mathrm{ClCH}_{3}+\mathrm{Br}^{-}$reaction. Because of the low intermolecular frequencies of the complexes, the heavy mass of $\mathrm{Br}$, and the long-distance ion-dipole interactions, the PES construction for this system is computationally very demanding despite consisting of only 6 atoms. In this study, the explicitly treated DoFs included the lengths of the bonds being formed and broken, as well as the doubly-degenerated low-frequency bending mode. The results showed that the most influential DoFs to the reaction rate constants are the 2 bond lengths. 
As shown in the last example, a key factor that affects the results of a RD calculation is the choice of the important DoFs to represent a complex reaction in the RD framework. However, this process can sometimes have an ambiguity in the chosen DoFs. An alternative method has been proposed which avoids the construction of a PES. In this "direct dynamics" simulation ${ }^{302}$, the $a b$ initio calculation is only called upon when the numerical integration at a point in a dynamics calculation requires the potential energy and, in some case, gradient. This approach is often referred to as "on the fly" calculation. This method is particularly powerful to study reactions with multiple completing mechanisms leading towards the same product, and reactions that do not follow the intrinsic reaction coordinates (IRC) that links reactants and products to the TS. It has been most extensively applied in a classical trajectory treatment of the nuclear dynamics with quantum chemistry calculations of somewhat limited accuracy due to the computational expense. However, the method does have considerable potential for the future as accurate quantum chemistry methods inevitably become more efficient and computers become faster. In due course this 'on the flight' type of method is likely to become a method of choice even for quantum dynamics calculations on polyatomic reactions and we thus give some examples here that illustrate its application in direct dynamics calculations.

One interesting example is the reaction between $\mathrm{F}^{-}$and $\mathrm{CH}_{3} \mathrm{OOH}^{303,304}$, which according to thermodynamic data should yield the IRC predicted most exothermic products of $\mathrm{HF}+\mathrm{CH}_{2}(\mathrm{OH}) \mathrm{O}^{-}$. However, experimental results showed that at temperatures as low as $300 \mathrm{~K}^{303}$, the much higher energy non-IRC products $\mathrm{HF}+\mathrm{CH}_{2} \mathrm{O}+\mathrm{OH}^{-}$were formed. The direct dynamics studies by López et al. ${ }^{303}$ investigated this behaviour. The analysis of the number of trajectories for the different reaction channels found that $23 \%$ formed $\mathrm{HF}+\mathrm{CH}_{2} \mathrm{O}+\mathrm{OH}^{-}$. The majority of these trajectories followed the pathway shows in Fig. 17, which provides theoretical evidence for the elimination mechanism proposed by the experimentalists. The study also showed that $48 \%$ of the trajectories were trapped in the $\mathrm{CH}_{3} \mathrm{OOH}-\mathrm{F}^{-}$vdW complex potential well, while the intramolecular vibrational energy redistribution was inefficient for breaking down the complex and form the most exothermic products and 
motions off the IRC resulted in the non-IRC reaction path.

The reactions between $\mathrm{CH}_{3}$ and $\mathrm{HOCO}$ radicals are important in the study of combustion. In combustion condition, several possible reaction channels are available. Yu and Francisco ${ }^{305}$ performed direct dynamics calculation over 4 thousand trajectories at six collision energies. The results showed the long-range attractive interaction between the reactants played an important role in the reaction as both the maximum impact parameter and the reaction cross section decreases as the collisional energy increases. More recently, Preston et al. ${ }^{306}$ performed direct dynamics calculation on the $\mathrm{Cl}+\mathrm{C}_{3} \mathrm{H}_{6} \rightarrow \mathrm{HCl}+\mathrm{C}_{3} \mathrm{H}_{5}$ reaction. It has two competing mechanisms. The reactants can undergo either a direct abstraction or an indirect addition-elimination mechanism to form the products. Due to the computational cost, the analysis was limited to only a few-hundred reactive trajectories, the calculation nevertheless showed insight into the reaction mechanism. About $90 \%$ of the reactive trajectories were from short-lived complexes, the reaction is dominated by direct abstraction.

Another type of reaction that is often studied uses the direct dynamics simulations involves formation of intermediates. For instance, the attacks on the $\mathrm{CH}_{3} \mathrm{I}$ molecule by $\mathrm{OH}^{-307,308}$ or $\mathrm{F}^{-309}$ anions. Xie et al. ${ }^{308}$ analysed the population of the possible product channels of the $\mathrm{OH}^{-}+\mathrm{CH}_{3} \mathrm{I}$ reactions using direct dynamics simulations. A total of five reaction pathways and multiple pre- and post-reaction complexes were observed in the simulation. The trajectories were selected for collision energies of $0.05,0.5,1.0$ and $2.0 \mathrm{eV}$. The calculation showed the shift in contribution of completing mechanisms. For the $\mathrm{S}_{\mathrm{N}} 2$ reaction pathway, the stripping and rebound direct reaction dominates at all collision energies, while the indirect reaction becomes more important than either of the direct mechanisms only at low energies. For the proton-transfer pathway, direct stripping is dominant at 2.0, 1.0 and $0.5 \mathrm{eV}$, while the majority of the reaction becomes indirect at $0.05 \mathrm{eV}$. In a later paper, Xie et al. ${ }^{307}$ investigated the effect of $\mathrm{OH}^{-}$rotational excitation on the dynamics of this reaction. The results showed that only the probability of the direct rebound mechanism increased with as $\mathrm{OH}^{-}$became rotationally excited, while other 
mechanisms were not affected. More recently, the proton transfer reaction of $\mathrm{F}^{-}+\mathrm{CH}_{3} \mathrm{I}$ was studied using direct dynamics simulations by Zhang et al. ${ }^{309}$ This reaction is endothermic, and hence a ZPE constraint of the product was taken into consideration. The majority of the product $\mathrm{CH}_{2} \mathrm{I}^{-}$anion was found to be highly rotationally excited. This was not found for the proton transfer pathway of the $\mathrm{OH}^{-}+\mathrm{CH}_{3} \mathrm{I}$ reaction, since it is exothermic and the product energy was mainly distributed in the relative translational motions. In the $\mathrm{F}^{-}+\mathrm{CH}_{3} \mathrm{I}$ case, with $\mathrm{ZPE}$ constraint, the energy partitioning is statistically the same to the vibrations, rotations of $\mathrm{CH}_{2} \mathrm{I}^{-}$and relative translations of $\mathrm{HF}+\mathrm{CH}_{2} \mathrm{I}^{-}$.

\section{Other approximate methods for reaction rate constant calculations}

When the reaction rate constant is the main interest, approximate methods can be used to provide good estimaes. Most of such approaches approximate the quantum scattering calculation in one way or another. Note that the most widely used method in calculating reaction rate constants for polyatomic reactions, the variational transition state theory with multidimensional tunnelling corrections (VTST/MT), will be reviewed in another article in this volume, and a detailed discussion is therefore not given here. QRS calculations are very useful in testing the accuracy of these more approximate methods for calculating rate constants.

One of the simplest and most cost-effective methods for calculating the rate constant of a reaction which has a relatively large barrier is the semiclassical transition state theory approach (SCTST). ${ }^{310-320}$ In this calculation, the full-dimensional energy barrier is approximated by a one-dimensional (1D) barrier constructed using the information of the PES near the TS, in particular the vibrational frequencies and anharmonic constants. The reaction probability is computed by the summation of the tunneling probabilities through the state-selective 1D PES barrier. Recently this method has been applied to the studies of several bimolecular and unimolecular reactions. ${ }^{313-320}$ The second order vibrational perturbation theory $(\mathrm{VPT} 2)^{312,321}$ was used to calculate the anharmonic constants. Stanton et al. ${ }^{314}$ tested the accuracy of the VPT2 method against higher order vibrational perturbation and 
found that VPT2 is sufficient for the rate constant calculation in SCTST and the effect of higher order perturbation theory might be approximated by a rescaling of the barrier frequency in VPT2 level. The accuracy of the approximations made in a SCTST calculation were tested by Greene et al. ${ }^{322}$ The reaction rate constants of various chemical reactions were calculated using SCTST and QRS on the same PESs. The SCTST rate constants showed excellent agreement with the QRS results.

One particularly interesting study was the calculation of $\mathrm{H}$-exchange $\mathrm{CH}_{3}$ $+\mathrm{CH}_{4}$ reaction, which is a $\mathrm{H}-\mathrm{L}-\mathrm{H}$ system with a light $\mathrm{H}$ atom transferred between two heavy $\mathrm{CH}_{3}$ radicals. In such reactions, corner-cutting effects have been shown to be important. ${ }^{295,323}$ The SCTST does not include considerations of the concave region of the PES between the reactant and product channels, however, the corner-cutting effect is indirectly treated in the barrier calculation with the coupling anharmonic constants and the coupling terms of the third-order derivatives of the PES. The resulting SCTST rate constant shows very good agreement to the quantum scattering result.

The latest FD SCTST application was to the previously discussed $\mathrm{OH}+\mathrm{NH}_{3} \rightarrow \mathrm{NH}_{2}+\mathrm{H}_{2} \mathrm{O}$ reaction ${ }^{313}$, where the rate constants calculation included the electronic partition function of the $\mathrm{OH}$ radical, 1D hindered rotor partition function to the internal rotation of the $\mathrm{NH}_{2}$ at the TS, vibrational partition function of the umbrella motion in the reactant $\mathrm{NH}_{3}$ and rescaling of the barrier frequencies. The resulting rate constants showed excellent agreement with the experimental and other theoretical results. A FD SCTST for systems that consists of more atoms can still be expensive, especially for the computation of the third and fourth order derivatives of the PES used in VPT2.

Simplifications to the FD SCTST, in particular RD SCTST, were first tested out by Nguyen et $a .^{319}$, and later by Greene et al. ${ }^{315,316}$, where 1D SCTST rate constants were compared to multi-dimensional SCTST results on $\mathrm{H}$-abstraction reactions of $\mathrm{H}$ with $\mathrm{CH}_{4}$ and $\mathrm{C}_{2} \mathrm{H}_{6}$. The studies showed that the deep tunneling correction ${ }^{324}$ to the semiclassical barrier is required for the best performance of a RD SCTST calculation. Greene et al. ${ }^{315}$ also suggested the use of the Richardson extrapolation method ${ }^{325}$ to improve the accuracy of higher-order derivatives obtained 
via numerical differentiation.

The ring polymer molecular dynamics (RPMD) is an approximate quantum mechanical approach that uses path integrals to calculate Kubo-transformed real-time correlation functions ${ }^{326,327}$. The resulting correlation functions coincide with the exact quantum mechanical result in the limit as $t \rightarrow 0$. A major advantage of this method is that the RPMD rate constant calculation is rigorously independent of the choice of the TS dividing surface that is used to calculate it ${ }^{328}$. This is highly desirable for applications to reactions for which the optimum dividing surface is difficult to determine. The method can be directly applied to systems for which conventional classical molecular dynamics simulations are applicable including systems with many atoms and also condensed phases. The RPMD has been applied to calculate the reaction rate constants of various $\mathrm{H}$ abstraction from organic molecules by atoms and radicals, including $\mathrm{H}+\mathrm{CH}_{4} \rightarrow \mathrm{H}_{2}+\mathrm{CH}_{3}{ }^{328-331}, \mathrm{O}+\mathrm{CH}_{4} \rightarrow \mathrm{OH}+\mathrm{CH}_{3}{ }^{332}$, ${ }^{333}, \mathrm{Cl}+\mathrm{CH}_{4} \rightarrow \mathrm{HCl}+\mathrm{CH}_{3}{ }^{334}, \mathrm{OH}+\mathrm{CH}_{4} \rightarrow \mathrm{H}_{2} \mathrm{O}+\mathrm{CH}_{3}{ }^{335},{ }^{336},{ }^{4} \mathrm{He} \mu+\mathrm{CH}_{4} \rightarrow$ $\mathrm{H}^{4} \mathrm{He} \mu+\mathrm{CH}_{3}{ }^{337}$ and $\mathrm{H}+$ ethane/propane/dimethyl ether ${ }^{338}$. One major computational cost of a RPMD calculation is the requirement of a global FD PES and a recent study that used local segmented PESs constructed by the permutation invariant polynomial neural network approach showed the possibility of reducing this cost. To date the approach has not been developed to allow for the calculation of dynamical quantities such as state-selected rate constants of cross sections and this would be an interesting challenge $\mathrm{e}^{338}$.

\section{Conclusions}

Quantum scattering calculations in the gas phase play an important role as they provide a highly accurate interpretation of experimental results on the details of chemical reactions. The calculations also provide essential quantities such as reaction rate constants which are used in many scientific applications. The calculations can be done for isotopic combinations and for a wide range of collision energies or temperatures, which is not always straightforward in experimental studies. As reaction 
dynamics experiments are being applied to more and more complicated systems there is a clear need for good quantum scattering calculations on reactions involving polyatomic molecule with more than three atoms. This review has summarized the recent progress. The advances have allowed for highly detailed comparisons with experiment and also the ability to test the accuracy of approximate approaches which can treat quantum aspects such as tunneling with a good accuracy for quite complicated reactions.

The field couples closely with advances in the theory and computational efficiency of $a b$ initio quantum chemistry methods and also with new procedures for constructing PESs for chemical reactions. Indeed, some practical approximate approaches remove the need for the construction of a global PES entirely. In parallel with the advances described here there has been progress in performing quantum scattering calculations on reactions occurring on solid surfaces. ${ }^{339}$ In this case it is more challenging to calculate $a b$ initio PESs of the same quality as achieved for the gas phase but the computations have still shown themselves to be useful. ${ }^{340}$ An even greater challenge is to extend the methods to the study of reactions in liquids. Some of the recent research using ring polymer molecular dynamics is showing promise in this direction. $^{341}$

\section{Acknowledgements}

B. Fu and D. H. Zhang acknowledge support from the National Natural Science Foundation of China (grants 21590804, 21433009, 21688102, and 21673233), Ministry of Science and Technology of China (2013CB834601), and Chinese Academy of Sciences (XDB17000000). X. Shan and D. Clary thank the Leverhulme Trust for financial support (Project Grant No. RPG-2013-321).

\section{References}


1. R. D. Levine, Molecular Reaction Dynamics, Cambridge University Press, Cambridge, 2005.

2. W. Hu and G. C. Schatz, The Journal of Chemical Physics, 2006, 125, 132301.

3. A. J. C. Varandas, in Advances in Chemical Physics, eds. I. Prigogine and S. A. Rice, John Wiley \& Sons, Inc., Hoboken, New Jersey, 1988, vol. 74, pp. 255-338.

4. T. Hollebeek, T.-S. Ho and H. Rabitz, Annual Review of Physical Chemistry, 1999, 50, 537-570.

5. M. A. Collins, Theoretical Chemistry Accounts, 2002, 108, 313-324.

6. R. Dawes, D. L. Thompson, Y. Guo, A. F. Wagner and M. Minkoff, The Journal of Chemical Physics, 2007, 126, 184108.

7. R. Dawes, D. L. Thompson, A. F. Wagner and M. Minkoff, The Journal of Chemical Physics, 2008, 128, 084107.

8. B. J. Braams and J. M. Bowman, International Reviews in Physical Chemistry, 2009, 28, 577-606.

9. J. M. Bowman, G. Czakó and B. Fu, Physical Chemistry Chemical Physics, 2011, 13, 8094-8111.

10. L. M. Raff, R. Komanduri, M. Hagan and S. Bukkapatnam, Neural networks in chemical reaction dynamics, Oxford University Press, New York, 2012.

11. J. Chen, X. Xu, X. Xu and D. H. Zhang, The Journal of Chemical Physics, 2013, 138, 154301.

12. J. Chen, X. Xu, X. Xu and D. H. Zhang, The Journal of Chemical Physics, 2013, 138, 221104.

13. B. Jiang and H. Guo, The Journal of Chemical Physics, 2013, 139, 054112.

14. J. Li, B. Jiang and H. Guo, The Journal of Chemical Physics, 2013, 139, 204103.

15. K. Shao, J. Chen, Z. Zhao and D. H. Zhang, The Journal of Chemical Physics, 2016, 145, 071101.

16. J. M. Bowman and G. C. Schatz, Annual Review of Physical Chemistry, 1995, 46, 169-196.

17. D. H. Zhang and J. Zhang, in Dynamics of molecules and chemical reactions, eds. R. E. Wyatt and J. Z. H. Zhang, Marcel Dekker, New York, 1996, p. 231.

18. J. Z. H. Zhang, J. Dai and W. Zhu, The Journal of Physical Chemistry A, 1997, 101, 2746-2754.

19. W. H. Miller, Journal of the Chemical Society, Faraday Transactions, 1997, 93, 685-690.

20. N. Balakrishnan, C. Kalyanaraman and N. Sathyamurthy, Physics Reports, 1997, 280, 79-144.

21. D. C. Clary, Science, 1998, 279, 1879-1882.

22. S. C. Althorpe and D. C. Clary, Annual Review of Physical Chemistry, 2003, 54, 493-529.

23. G. G. Balint-Kurti, International Reviews in Physical Chemistry, 2008, 27, 507-539.

24. C. Xiao, X. Xu, S. Liu, T. Wang, W. Dong, T. Yang, Z. Sun, D. Dai, X. Xu, D. H. Zhang and X. Yang, Science, 2011, 333, 440-442.

25. H. Guo, International Reviews in Physical Chemistry, 2012, 31, 1-68.

26. D. R. Yarkony, Chemical Reviews, 2012, 112, 481-498.

27. G. Nyman and H.-G. Yu, International Reviews in Physical Chemistry, 2013, 32, 39-95.

28. R. Otto, J. Ma, A. W. Ray, J. S. Daluz, J. Li, H. Guo and R. E. Continetti, Science, 2014, 343, 396-399.

29. D. H. Zhang and H. Guo, Annual Review of Physical Chemistry, 2016, 67, 135-158.

30. K. Liu, Annual Review of Physical Chemistry, 2001, 52, 139-164.

31. F. Fernández-Alonso and R. N. Zare, Annual Review of Physical Chemistry, 2002, 53, 67-99.

32. M. Brouard, P. O'Keeffe and C. Vallance, The Journal of Physical Chemistry A, 2002, 106, 3629-3641.

33. N. Balucani, G. Capozza, F. Leonori, E. Segoloni and P. Casavecchia, International Reviews in Physical Chemistry, 2006, 25, 109-163.

34. X. Yang, Annual Review of Physical Chemistry, 2007, 58, 433-459. 
35. F. F. Crim, Proceedings of the National Academy of Sciences, 2008, 105, 12654-12661.

36. K. Liu, in Advances in Chemical Physics, eds. S. A. Rice and A. R. Dinner, John Wiley \& Sons, Inc., Hoboken, New Jersey, 2012, vol. 149, pp. 1-46.

37. H. Guo and K. Liu, Chemical Science, 2016, 7, 3992-4003.

38. M. Qiu, Z. Ren, L. Che, D. Dai, S. A. Harich, X. Wang, X. Yang, C. Xu, D. Xie, M. Gustafsson, R. T. Skodje, Z. Sun and D. H. Zhang, Science, 2006, 311, 1440-1443.

39. L. Che, Z. Ren, X. Wang, W. Dong, D. Dai, X. Wang, D. H. Zhang, X. Yang, L. Sheng, G. Li, H.-J. Werner, F. Lique and M. H. Alexander, Science, 2007, 317, 1061-1064.

40. X. Wang, W. Dong, C. Xiao, L. Che, Z. Ren, D. Dai, X. Wang, P. Casavecchia, X. Yang, B. Jiang, D. Xie, Z. Sun, S.-Y. Lee, D. H. Zhang, H.-J. Werner and M. H. Alexander, Science, 2008, 322, 573-576.

41. T. Wang, J. Chen, T. Yang, C. Xiao, Z. Sun, L. Huang, D. Dai, X. Yang and D. H. Zhang, Science, 2013, 342, 1499-1502.

42. T. Yang, J. Chen, L. Huang, T. Wang, C. Xiao, Z. Sun, D. Dai, X. Yang and D. H. Zhang, Science, 2015, 347, 60-63.

43. G. C. Schatz and A. Kuppermann, The Journal of Chemical Physics, 1976, 65, 4668-4692.

44. M. Mladenovic, M. Zhao, D. G. Truhlar, D. W. Schwenke, Y. Sun and D. J. Kouri, The Journal of Physical Chemistry, 1988, 92, 7035-7038.

45. W. Zhang, Y. Zhou, G. Wu, Y. Lu, H. Pan, B. Fu, Q. Shuai, L. Liu, S. Liu, L. Zhang, B. Jiang, D. Dai, S.-Y. Lee, Z. Xie, B. J. Braams, J. M. Bowman, M. A. Collins, D. H. Zhang and X. Yang, Proceedings of the National Academy of Sciences, 2010, 107, 12782-12785.

46. Z. Zhang, Y. Zhou, D. H. Zhang, G. Czakó and J. M. Bowman, The Journal of Physical Chemistry Letters, 2012, 3, 3416-3419.

47. R. Liu, H. Xiong and M. Yang, The Journal of Chemical Physics, 2012, 137, 174113.

48. R. Liu, M. Yang, G. Czakó, J. M. Bowman, J. Li and H. Guo, The Journal of Physical Chemistry Letters, 2012, 3, 3776-3780.

49. R. Welsch and U. Manthe, The Journal of Physical Chemistry Letters, 2015, 6, 338-342.

50. Z. Zhao, Z. Zhang, S. Liu and D. H. Zhang, Nature Communications, 2017, 8, 14506.

51. A. Kuppermann and P. G. Hipes, The Journal of Chemical Physics, 1986, 84, 5962-5964.

52. R. T. Pack and G. A. Parker, The Journal of Chemical Physics, 1987, 87, 3888-3921.

53. D. Skouteris, J. F. Castillo and D. E. Manolopoulos, Computer Physics Communications, 2000, 133, 128-135.

54. D. Skouteris, D. E. Manolopoulos, W. Bian, H.-J. Werner, L.-H. Lai and K. Liu, Science, 1999, 286, 1713-1716.

55. S. A. Harich, D. Dai, C. C. Wang, X. Yang, S. D. Chao and R. T. Skodje, Nature, 2002, 419, 281-284.

56. D. Dai, C. C. Wang, S. A. Harich, X. Wang, X. Yang, S. Der Chao and R. T. Skodje, Science, 2003, 300, 1730-1734.

57. P. Honvault and J.-M. Launay, Theory of Chemical Reaction Dynamics, Kluwer, Dordrecht, The Netherlands, 2004.

58. V. Aquilanti and S. Cavalli, Journal of the Chemical Society, Faraday Transactions, 1997, 93, 801-809.

59. S. K. Pogrebnya, J. Echave and D. C. Clary, The Journal of Chemical Physics, 1997, 107, 8975-8984. 
60. R. Kosloff, The Journal of Physical Chemistry, 1988, 92, 2087-2100.

61. J. Z. H. Zhang, Theory and Application of Quantum Molecular Dynamics, World Scientific, Singapore, 1998.

62. E. M. Goldfield and S. K. Gray, in Advances in Chemical Physics, ed. S. A. Rice, John Wiley \& Sons, Inc., Hoboken, New Jersey, 2007, vol. 136, pp. 1-38.

63. D. Neuhauser, M. Baer, R. S. Judson and D. J. Kouri, Computer Physics Communications, 1991, 63, 460-481.

64. Z. Sun, W. Yang and D. H. Zhang, Physical Chemistry Chemical Physics, 2012, 14, 1827-1845.

65. S. K. Gray and G. G. Balint-Kurti, The Journal of Chemical Physics, 1998, 108, 950-962.

66. S. C. Althorpe, The Journal of Chemical Physics, 2001, 114, 1601-1616.

67. K. Yuan, Y. Cheng, X. Liu, S. Harich, X. Yang and D. H. Zhang, Physical Review Letters, 2006, 96, 103202.

68. S. Y. Lin and H. Guo, Physical Review A, 2006, 74, 022703.

69. M. Hankel, S. C. Smith, R. J. Allan, S. K. Gray and G. G. Balint-Kurti, The Journal of Chemical Physics, 2006, 125, 164303.

70. S. Gómez-Carrasco and O. Roncero, The Journal of Chemical Physics, 2006, 125, 054102.

71. Z. Sun, H. Guo and D. H. Zhang, The Journal of Chemical Physics, 2010, 132, 084112.

72. T. Peng and J. Z. H. Zhang, The Journal of Chemical Physics, 1996, 105, 6072-6074.

73. M. T. Cvitaš and S. C. Althorpe, The Journal of Chemical Physics, 2011, 134, 024309.

74. S. Liu, X. Xu and D. H. Zhang, The Journal of Chemical Physics, 2011, 135, 141108.

75. S. Liu, X. Xu and D. H. Zhang, The Journal of Chemical Physics, 2012, 136, 144302.

76. M. T. Cvitaš and S. C. Althorpe, The Journal of Chemical Physics, 2013, 139, 064307.

77. S. C. Althorpe, D. J. Kouri and D. K. Hoffman, The Journal of Chemical Physics, 1997, 106, 7629-7636.

78. R. Welsch, F. Huarte-Larrañaga and U. Manthe, The Journal of Chemical Physics, 2012, 136, 064117.

79. U. Manthe and R. Welsch, The Journal of Chemical Physics, 2014, 140, 244113.

80. W. H. Miller, The Journal of Chemical Physics, 1974, 61, 1823-1834.

81. R. Welsch and U. Manthe, Molecular Physics, 2012, 110, 703-715.

82. B. Zhao, Z. Sun and H. Guo, The Journal of Chemical Physics, 2014, 140, 234110.

83. B. Zhao, Z. Sun and H. Guo, Journal of the American Chemical Society, 2015, 137, 15964-15970.

84. B. Zhao and H. Guo, The Journal of Physical Chemistry Letters, 2015, 6, 676-680.

85. J. Warnatz, in Combustion Chemistry, ed. W. C. G. Jr., Springer-Verlag, New York, 1984, vol. Chapter 5, pp. 197-360.

86. T. J. Millar and D. A. Williams, Rate Coefficients in Astrochemistry, Kluwer, Dordrecht, Umis, Manchester, U.K., 1987.

87. A. Sinha, M. C. Hsiao and F. F. Crim, The Journal of Chemical Physics, 1990, 92, 6333-6335.

88. A. Sinha, M. C. Hsiao and F. F. Crim, The Journal of Chemical Physics, 1991, 94, 4928-4935.

89. F. F. Crim, Accounts of Chemical Research, 1999, 32, 877-884.

90. M. J. Bronikowski, W. R. Simpson, B. Girard and R. N. Zare, The Journal of Chemical Physics, 1991, 95, 8647-8648.

91. M. J. Bronikowski, W. R. Simpson and R. N. Zare, The Journal of Physical Chemistry, 1993, 97, 2204-2208. 
92. R. N. Zare, Science, 1998, 279, 1875-1879.

93. G. Ochoa de Aspuru and D. C. Clary, The Journal of Physical Chemistry A, 1998, 102, 9631-9637.

94. S. K. Pogrebnya, J. Palma, D. C. Clary and J. Echave, Physical Chemistry Chemical Physics, 2000, 2, 693-700.

95. G.-S. Wu, G. C. Schatz, G. Lendvay, D.-C. Fang and L. B. Harding, The Journal of Chemical Physics, 2000, 113, 3150-3161.

96. M. Yang, D. H. Zhang, M. A. Collins and S.-Y. Lee, The Journal of Chemical Physics, 2001, 115, 174-178.

97. M. T. Cvitaš and S. C. Althorpe, The Journal of Physical Chemistry A, 2009, 113, 4557-4569.

98. T. C. Marko and C. A. Stuart, Physica Scripta, 2009, 80, 048115.

99. S. Liu, C. Xiao, T. Wang, J. Chen, T. Yang, X. Xu, D. H. Zhang and X. Yang, Faraday Discussions, 2012, 157, 101-111.

100. Z. Zhao, S. Liu and D. H. Zhang, The Journal of Chemical Physics, 2016, 145, 134301.

101. B. Zhao, Z. Sun and H. Guo, The Journal of Chemical Physics, 2016, 145, 134308.

102. B. Zhao, Z. Sun and H. Guo, The Journal of Chemical Physics, 2014, 141, 154112.

103. B. Zhao, Z. Sun and H. Guo, The Journal of Chemical Physics, 2016, 145, 184106.

104. Z. Sun, X. Lin, S.-Y. Lee and D. H. Zhang, The Journal of Physical Chemistry A, 2009, 113, 4145-4154.

105. K. Kudla and G. C. Schatz, The Journal of Chemical Physics, 1993, 98, 4644-4651.

106. J. M. Bowman and D. Wang, The Journal of Chemical Physics, 1992, 96, 7852-7854.

107. D. Wang and J. M. Bowman, The Journal of Chemical Physics, 1993, 98, 6235-6247.

108. D. C. Clary, Chemical Physics Letters, 1992, 192, 34-40.

109. D. C. Clary, The Journal of Chemical Physics, 1992, 96, 3656-3665.

110. G. Nyman and D. C. Clary, The Journal of Chemical Physics, 1993, 99, 7774-7786.

111. J. Echave and D. C. Clary, The Journal of Chemical Physics, 1994, 100, 402-422.

112. D. H. Zhang and J. C. Light, Journal of the Chemical Society, Faraday Transactions, 1997, 93, 691-697.

113. D. H. Zhang, M. A. Collins and S.-Y. Lee, Science, 2000, 290, 961-963.

114. B. Jiang, D. Xie and H. Guo, The Journal of Chemical Physics, 2011, 135, 084112.

115. B. Fu and D. H. Zhang, The Journal of Chemical Physics, 2013, 138, 184308.

116. B. Fu and D. H. Zhang, The Journal of Chemical Physics, 2015, 142, 064314.

117. M. T. Hagan and M. B. Menhaj, IEEE Transactions on Neural Networks, 1994, 5, 989-993.

118. L. M. Raff, M. Malshe, M. Hagan, D. I. Doughan, M. G. Rockley and R. Komanduri, The Journal of Chemical Physics, 2005, 122, 084104.

119. B. Jiang and H. Guo, Journal of the American Chemical Society, 2013, 135, 15251-15256.

120. B. Jiang and H. Guo, The Journal of Chemical Physics, 2013, 138, 234104.

121. H. Guo and B. Jiang, Accounts of Chemical Research, 2014, 47, 3679-3685.

122. S. Liu and D. H. Zhang, Chemical Science, 2016, 7, 261-265.

123. Z.-q. Zhao, S. Liu and D. H. Zhang, Chinese Journal of Chemical Physics, 2017, 30, 16-24.

124. D. H. Zhang, M. Yang and S.-Y. Lee, Physical Review Letters, 2002, 89, 103201.

125. B. Fu, Y. Zhou and D. H. Zhang, Chemical Science, 2012, 3, 270-274.

126. B. Fu and D. H. Zhang, The Journal of Physical Chemistry A, 2012, 116, 820-825.

127. B. Fu and D. H. Zhang, The Journal of Chemical Physics, 2012, 136, 194301. 
128. A. M. Zolot and D. J. Nesbitt, The Journal of Chemical Physics, 2008, 129, 184305.

129. M. Ziemkiewicz and D. J. Nesbitt, The Journal of Chemical Physics, 2009, 131, 054309.

130. J. C. Polanyi, Accounts of Chemical Research, 1972, 5, 161-168.

131. J. Li, B. Jiang and H. Guo, Chemical Science, 2013, 4, 629-632.

132. J. Li, B. Jiang and H. Guo, Journal of the American Chemical Society, 2013, 135, 982-985.

133. J. Li, R. Dawes and H. Guo, The Journal of Chemical Physics, 2012, 137, 094304.

134. H. Song, J. Li and H. Guo, The Journal of chemical physics, 2014, 141, 164316.

135. H. Song and H. Guo, The Journal of Chemical Physics, 2015, 142, 174309.

136. A. Sinha, J. D. Thoemke and F. F. Crim, The Journal of Chemical Physics, 1992, 96, 372-376.

137. J. D. Thoemke, J. M. Pfeiffer, R. B. Metz and F. F. Crim, The Journal of Physical Chemistry, 1995, 99, 13748-13754.

138. J. Li, B. Jiang, H. Song, J. Ma, B. Zhao, R. Dawes and H. Guo, The Journal of Physical Chemistry A, 2015, 119, 4667-4687.

139. H. Song and H. Guo, The Journal of Physical Chemistry A, 2015, 119, 6188-6194.

140. H. Song and H. Guo, The Journal of Physical Chemistry A, 2015, 119, 826-831.

141. J. Li, H. Song and H. Guo, Physical Chemistry Chemical Physics, 2015, 17, 4259-4267.

142. J. M. Bowman, The Journal of Physical Chemistry, 1991, 95, 4960-4968.

143. B. Zhao, Z. Sun and H. Guo, The Journal of Chemical Physics, 2015, 142, 241101.

144. J. Li and H. Guo, The Journal of Chemical Physics, 2013, 138, 194304.

145. D. Lu and J. Li, The Journal of Chemical Physics, 2016, 145, 014303.

146. J. Qi, D. Lu, H. Song, J. Li and M. Yang, The Journal of Chemical Physics, 2017, 146, 124303.

147. D. Lu, J. Qi, M. Yang, J. Behler, H. Song and J. Li, Physical Chemistry Chemical Physics, 2016, 18, 29113-29121.

148. Finlayson-Pitts, B. J. and J. N. Pitts, Chemistry of the Lower and Upper Atmosphere:Theory, Experiments, and Applications, Academic Press, San Diego, 2000.

149. J A Miller, a. R J Kee and C. K. Westbrook, Annual Review of Physical Chemistry, 1990, 41, 345-387.

150. D. Fulle, H. F. Hamann, H. Hippler and J. Troe, The Journal of Chemical Physics, 1996, 105, 983-1000.

151. D. M. Golden, G. P. Smith, A. B. McEwen, C. L. Yu, B. Eiteneer, M. Frenklach, G. L. Vaghjiani, A. R. Ravishankara and F. P. Tully, The Journal of Physical Chemistry A, 1998, 102, 8598-8606.

152. M. Alagia, N. Balucani, P. Casavecchia, D. Stranges and G. G. Volpi, The Journal of Chemical Physics, 1993, 98, 8341-8344.

153. P. Casavecchia, N. Balucani and G. G. Volpi, in The Chemical Dynamics and Kinetics of Small Radicals, eds. K. Liu and A. Wagner, World Scientific, Singapore, 1995, vol. Part 1, pp. 365-437.

154. G. C. Schatz, M. S. Fitzcharles and L. B. Harding, Faraday Discussions of the Chemical Society, 1987, 84, 359-369.

155. K. Kudla, A. G. Koures, L. B. Harding and G. C. Schatz, The Journal of Chemical Physics, 1992, 96, 7465-7473.

156. K. S. Bradley and G. C. Schatz, The Journal of Chemical Physics, 1997, 106, 8464-8472.

157. H.-G. Yu, J. T. Muckerman and T. J. Sears, Chemical Physics Letters, 2001, 349, 547-554.

158. M. J. Lakin, D. Troya, G. C. Schatz and L. B. Harding, The Journal of Chemical Physics, 2003, 119, 5848-5859. 
159. R. Valero and G.-J. Kroes, Chemical Physics Letters, 2006, 417, 43-47.

160. J. Li, Y. Wang, B. Jiang, J. Ma, R. Dawes, D. Xie, J. M. Bowman and H. Guo, The Journal of Chemical Physics, 2012, 136, 041103.

161. J. Li, C. Xie, J. Ma, Y. Wang, R. Dawes, D. Xie, J. M. Bowman and H. Guo, The Journal of Physical Chemistry A, 2012, 116, 5057-5067.

162. J. Behler, Physical Chemistry Chemical Physics, 2011, 13, 17930-17955.

163. J. Li, J. Chen, D. H. Zhang and H. Guo, The Journal of Chemical Physics, 2014, 140, 044327.

164. D. M. Medvedev, S. K. Gray, E. M. Goldfield, M. J. Lakin, D. Troya and G. C. Schatz, The Journal of Chemical Physics, 2004, 120, 1231-1238.

165. R. Valero, D. A. McCormack and G.-J. Kroes, The Journal of Chemical Physics, 2004, 120, 4263-4272.

166. R. Valero and G.-J. Kroes, The Journal of Physical Chemistry A, 2004, 108, 8672-8681.

167. S. Liu, X. Xu and D. H. Zhang, Theoretical Chemistry Accounts, 2012, 131, 1068.

168. J. Ma, J. Li and H. Guo, The Journal of Physical Chemistry Letters, 2012, 3, 2482-2486.

169. C. Wang, S. Liu and D. H. Zhang, Chemical Physics Letters, 2012, 537, 16-20.

170. S. Liu, J. Chen, B. Fu and D. H. Zhang, Theoretical Chemistry Accounts, 2014, 133, 1558.

171. X. Q. Zhang, Q. Cui, J. Z. H. Zhang and K. L. Han, The Journal of Chemical Physics, 2007, 126, 234304.

172. M. Yang and J. C. Corchado, The Journal of Chemical Physics, 2007, 126, 214312.

173. M. Yang and J. C. Corchado, The Journal of Chemical Physics, 2007, 127, 184308.

174. J. C. Corchado and J. Espinosa-García, The Journal of Chemical Physics, 1997, 106, 4013-4021.

175. M. Yang, The Journal of Chemical Physics, 2008, 129, 064315.

176. J. C. Corchado, J. Espinosa-Garcia and M. Yang, The Journal of Chemical Physics, 2011, 135, 014303.

177. J. Espinosa-Garcia and J. C. Corchado, The Journal of Physical Chemistry A, 2010, 114, 4455-4463.

178. J. Li and H. Guo, Physical Chemistry Chemical Physics, 2014, 16, 6753-6763.

179. H. Song, M. Yang and H. Guo, The Journal of Chemical Physics, 2016, 145, 131101.

180. H. Song, J. Li, M. Yang, Y. Lu and H. Guo, Physical Chemistry Chemical Physics, 2014, 16, 17770-17776.

181. H. Song and H. Guo, The Journal of Chemical Physics, 2014, 141, 244311.

182. K. H. Homann and H. G. Wagner, Proceedings of the Royal Society of London. Series A, Mathematical and Physical Sciences, 1968, 307, 141-152.

183. G. R. Gladstone, M. Allen and Y. L. Yung, Icarus, 1996, 119, 1-52.

184. J. E. Murphy, A. B. Vakhtin and S. R. Leone, Icarus, 2003, 163, 175-181.

185. D. E. Woon and J.-Y. Park, Icarus, 2009, 202, 642-655.

186. D. Wang, The Journal of Chemical Physics, 2003, 119, 12057-12062.

187. D. Wang, The Journal of Chemical Physics, 2003, 118, 1184-1188.

188. D. Wang, The Journal of Chemical Physics, 2005, 123, 194302.

189. D. Wang, The Journal of Chemical Physics, 2006, 124, 201105.

190. D. Wang and J. M. Bowman, The Journal of Chemical Physics, 1994, 101, 8646-8662.

191. A. R. Sharma, B. J. Braams, S. Carter, B. C. Shepler and J. M. Bowman, The Journal of Chemical Physics, 2009, 130, 174301.

192. J. M. Smith, M. Nikow, J. Ma, M. J. Wilhelm, Y.-C. Han, A. R. Sharma, J. M. Bowman and H.-L. 
Dai, Journal of the American Chemical Society, 2014, 136, 1682-1685.

193. Y.-C. Han, A. R. Sharma and J. M. Bowman, The Journal of Chemical Physics, 2012, 136, 214313.

194. D. Wang and W. M. Huo, The Journal of Chemical Physics, 2007, 127, 154304.

195. D. Wang and W. M. Huo, The Journal of Chemical Physics, 2008, 129, 084303.

196. D. Wang and W. M. Huo, Chemical Physics Letters, 2010, 490, 4-8.

197. L. Chen, K. Shao, J. Chen, M. Yang and D. H. Zhang, The Journal of Chemical Physics, 2016, 144, 194309.

198. J. P. Camden, H. A. Bechtel and R. N. Zare, Angewandte Chemie International Edition, 2003, 42, 5227-5230.

199. J. P. Camden, H. A. Bechtel, D. J. A. Brown and R. N. Zare, The Journal of Chemical Physics, 2005, 123, 134301.

200. J. P. Camden, H. A. Bechtel, D. J. Ankeny Brown, M. R. Martin, R. N. Zare, W. Hu, G. Lendvay, D. Troya and G. C. Schatz, Journal of the American Chemical Society, 2005, 127, 11898-11899.

201. J. P. Camden, W. Hu, H. A. Bechtel, D. J. A. Brown, M. R. Martin, R. N. Zare, G. Lendvay, D. Troya and G. C. Schatz, The Journal of Physical Chemistry A, 2006, 110, 677-686.

202. W. Hu, G. Lendvay, D. Troya, G. C. Schatz, J. P. Camden, H. A. Bechtel, D. J. A. Brown, M. R. Martin and R. N. Zare, The Journal of Physical Chemistry A, 2006, 110, 3017-3027.

203. M. J. T. Jordan and R. G. Gilbert, The Journal of Chemical Physics, 1995, 102, 5669-5682.

204. J. Espinosa-García and J. C. Corchado, The Journal of Physical Chemistry, 1996, 100, 16561-16567.

205. T. Wu, H.-J. Werner and U. Manthe, Science, 2004, 306, 2227-2229.

206. X. Zhang, B. J. Braams and J. M. Bowman, The Journal of Chemical Physics, 2006, 124, 021104.

207. Z. Xie, J. M. Bowman and X. Zhang, The Journal of Chemical Physics, 2006, 125, 133120.

208. Y. Zhou, B. Fu, C. Wang, M. A. Collins and D. H. Zhang, The Journal of Chemical Physics, 2011, 134, 064323.

209. R. Welsch and U. Manthe, The Journal of Chemical Physics, 2013, 138, 164118.

210. X. Xu, J. Chen and D. H. Zhang, Chinese Journal of Chemical Physics, 2014, 27, 373-379.

211. J. Li, J. Chen, Z. Zhao, D. Xie, D. H. Zhang and H. Guo, The Journal of Chemical Physics, 2015, 142, 204302.

212. M. Yang, D. H. Zhang and S.-Y. Lee, The Journal of Chemical Physics, 2002, 117, 9539-9542.

213. M. Yang, S.-Y. Lee and D. H. Zhang, The Journal of Chemical Physics, 2007, 126, 064303.

214. J. Palma and D. C. Clary, The Journal of Chemical Physics, 2000, 112, 1859-1867.

215. Y. Zhou, C. Wang and D. H. Zhang, The Journal of Chemical Physics, 2011, 135, 024313.

216. S. Liu, J. Chen, Z. Zhang and D. H. Zhang, The Journal of Chemical Physics, 2013, 138, 011101.

217. Z. Zhang, J. Chen, S. Liu and D. H. Zhang, The Journal of Chemical Physics, 2014, 140, 224304.

218. Z. Zhang and D. H. Zhang, The Journal of Chemical Physics, 2014, 141, 144309.

219. L. Zhang, Y. Lu, S.-Y. Lee and D. H. Zhang, The Journal of Chemical Physics, 2007, 127, 234313.

220. Y. Zhou and D. H. Zhang, The Journal of Chemical Physics, 2014, 141, 194307.

221. Y. Wang, J. Li, L. Chen, Y. Lu, M. Yang and H. Guo, The Journal of Chemical Physics, 2015, 143, 154307.

222. Z. Zhang, J. Chen, M. Yang and D. H. Zhang, The Journal of Physical Chemistry A, 2015, 119, 12480-12484. 
223. G. Schiffel and U. Manthe, The Journal of Chemical Physics, 2010, 132, 191101.

224. G. Schiffel and U. Manthe, The Journal of Chemical Physics, 2010, 133, 174124.

225. R. Welsch and U. Manthe, The Journal of Chemical Physics, 2014, 141, 051102.

226. R. Welsch and U. Manthe, The Journal of Chemical Physics, 2014, 141, 174313.

227. R. Welsch and U. Manthe, The Journal of Chemical Physics, 2015, 142, 064309.

228. R. Ellerbrock and U. Manthe, Chemical Physics, 2017, 482, 106-112.

229. U. Manthe and R. Ellerbrock, The Journal of Chemical Physics, 2016, 144, 204119.

230. W. Zhang, H. Kawamata and K. Liu, Science, 2009, 325, 303-306.

231. J. Yang, D. Zhang, B. Jiang, D. Dai, G. Wu, D. Zhang and X. Yang, The Journal of Physical Chemistry Letters, 2014, 5, 1790-1794.

232. J. Yang, D. Zhang, Z. Chen, F. Blauert, B. Jiang, D. Dai, G. Wu, D. Zhang and X. Yang, The Journal of Chemical Physics, 2015, 143, 044316.

233. G. Czakó and J. M. Bowman, Journal of the American Chemical Society, 2009, 131, 17534-17535.

234. G. Czakó and J. M. Bowman, The Journal of Chemical Physics, 2009, 131, 244302.

235. G. Czakó, B. C. Shepler, B. J. Braams and J. M. Bowman, The Journal of Chemical Physics, 2009, 130, 084301.

236. T. Westermann, W. Eisfeld and U. Manthe, The Journal of Chemical Physics, 2013, 139, 014309.

237. J. Palma and U. Manthe, The Journal of Physical Chemistry A, 2015, 119, 12209-12217.

238. G. Nyman and J. Espinosa-García, The Journal of Physical Chemistry A, 2007, 111, 11943-11947.

239. T. Chu, K. Han and J. Espinosa-Garcia, The Journal of Chemical Physics, 2009, 131, 244303.

240. H. F. von Horsten and D. C. Clary, Physical Chemistry Chemical Physics, 2011, 13, 4340-4356.

241. D. Wang and G. Czakó, The Journal of Physical Chemistry A, 2013, 117, 7124-7130.

242. J. Qi, H. Song, M. Yang, J. Palma, U. Manthe and H. Guo, The Journal of Chemical Physics, 2016, 144, 171101.

243. S. Yan, Y.-T. Wu, B. Zhang, X.-F. Yue and K. Liu, Science, 2007, 316, 1723-1726.

244. S. Yan, Y.-T. Wu and K. Liu, Proceedings of the National Academy of Sciences, 2008, 105, 12667-12672.

245. G. Czakó and J. M. Bowman, Science, 2011, 334, 343-346.

246. G. Czakó and J. M. Bowman, The Journal of Chemical Physics, 2012, 136, 044307.

247. F. Wang, J.-S. Lin, Y. Cheng and K. Liu, The Journal of Physical Chemistry Letters, 2013, 4, 323-327.

248. R. Liu, F. Wang, B. Jiang, G. Czakó, M. Yang, K. Liu and H. Guo, The Journal of Chemical Physics, 2014, 141, 074310.

249. N. Liu and M. Yang, The Journal of Chemical Physics, 2015, 143, 134305.

250. B. Zhang and K. Liu, The Journal of Chemical Physics, 2005, 122, 101102.

251. Y.-T. Wu and K. Liu, The Journal of Chemical Physics, 2008, 129, 154302.

252. Y.-R. Tzeng and M. H. Alexander, The Journal of Chemical Physics, 2004, 121, 5812.

253. S. M. Remmert, S. T. Banks, J. N. Harvey, A. J. Orr-Ewing and D. C. Clary, The Journal of Chemical Physics, 2011, 134, 204311.

254. X. Shan, S. M. Remmert, D. C. Clary, B. Zhang and K. Liu, Chemical Physics Letters, 2013, 587, 88-92. 
255. W. C. Gardiner Jr., in Combustion Chemistry, ed. W. C. Gardiner Jr., Springer-Verlag, New York, 1984, vol. Chapter 1, pp. 1-19.

256. F. Wang and K. Liu, Chemical Science, 2010, 1, 126-133.

257. B. Zhang and K. Liu, The Journal of Physical Chemistry A, 2005, 109, 6791-6795.

258. J. Zhang, S. A. Lahankar, D. J. Garton, T. K. Minton, W. Zhang and X. Yang, The Journal of Physical Chemistry A, 2011, 115, 10894-10902.

259. J. Zhang and K. Liu Chemistry - An Asian Journal, 2011, 6, 3132-3136.

260. R. Martínez, P. A. Enríquez, M. P. Puyuelo and M. González, The Journal of Physical Chemistry A, 2012, 116, 5026-5029.

261. G. Czakó, R. Liu, M. Yang, J. M. Bowman and H. Guo, The Journal of Physical Chemistry A, 2013, 117, 6409-6420.

262. J. Palma and D. C. Clary, Physical Chemistry Chemical Physics, 2000, 2, 4105-4114.

263. H.-G. Yu and G. Nyman, The Journal of Chemical Physics, 2000, 112, 238-247.

264. M.-L. Wang, Y.-M. Li and J. Z. H. Zhang, The Journal of Physical Chemistry A, 2001, 105, 2530-2534.

265. W. Yan, F. Meng and D. Wang, The Journal of Physical Chemistry A, 2013, 117, 12236-12242.

266. G. Czakó and J. M. Bowman, Proceedings of the National Academy of Sciences, 2012, 109, 7997-8001.

267. I. Glassman, Combustion, Academic Press, San Diego, California, 1996.

268. I. M. Campbell, in Energy and the Atmosphere, John Wiley \& Sons Ltd., London,UK, 1977, vol. 82, pp. 555-556.

269. N. K. Srinivasan, M. C. Su, J. W. Sutherland and J. V. Michael, The Journal of Physical Chemistry A, 2005, 109, 1857-1863.

270. B. Zhang, W. Shiu, J. J. Lin and K. Liu, The Journal of Chemical Physics, 2005, 122, 131102.

271. B. Zhang, W. Shiu and K. Liu, The Journal of Physical Chemistry A, 2005, 109, 8983-8988.

272. B. Zhang, W. Shiu and K. Liu, The Journal of Physical Chemistry A, 2005, 109, 8989-8993.

273. G. Nyman and D. C. Clary, The Journal of Chemical Physics, 1994, 101, 5756-5771.

274. G. Nyman, D. C. Clary and R. D. Levine, Chemical Physics, 1995, 191, 223-233.

275. H.-G. Yu, The Journal of Chemical Physics, 2001, 114, 2967-2976.

276. H. Song, S.-Y. Lee, M. Yang and Y. Lu, The Journal of Chemical Physics, 2013, 139, 154310.

277. H. Song, J. Li, B. Jiang, M. Yang, Y. Lu and H. Guo, The Journal of Chemical Physics, 2014, 140, 084307.

278. J. Espinosa-García and J. C. Corchado, The Journal of Chemical Physics, 2000, 112, 5731-5739.

279. J. Li and H. Guo, The Journal of Chemical Physics, 2015, 143, 221103.

280. H. Song, Y. Lu, J. Li, M. Yang and H. Guo, The Journal of Chemical Physics, 2016, 144, 164303.

281. M. L. Weichman, J. A. DeVine, M. C. Babin, J. Li, L. Guo, J. Ma, H. Guo and D. M. Neumark, Nat Chem, 2017, 9, 950-955.

282. D. C. Clary, Science, 2008, 321.

283. J. M. Bowman, Theoretical Chemistry Accounts, 2002, 108, 125-133.

284. S. T. Banks and D. C. Clary, The Journal of Chemical Physics, 2009, 130, 024106.

285. S. T. Banks, C. S. Tautermann, S. M. Remmert and D. C. Clary, The Journal of Chemical Physics, 2009, 131, 044111.

286. S. M. Remmert, S. T. Banks and D. C. Clary, The Journal of Physical Chemistry A, 2009, 113, 4255-4264. 
287. H. F. von Horsten, S. T. Banks and D. C. Clary, The Journal of Chemical Physics, 2011, 135, 094311.

288. B. C. Kerkeni, David C., Chemical Physics Letters, 2007, 438, 1-7.

289. I. Oueslati, B. Kerkeni and W.-Ü. L. Tchang-Brillet, Chemical Physics Letters, 2015, 624, 29-36.

290. A. Siaï, I. Oueslati and B. Kerkeni, Chemical Physics, 2016, 474, 44-51.

291. X. Shan and D. C. Clary, Physical Chemistry Chemical Physics, 2013, 15, 1222-1231.

292. X. Shan and D. C. Clary, The Journal of Physical Chemistry A, 2014, 118, 10134-10143.

293. X. Shan and D. C. Clary, Physical Chemistry Chemical Physics, 2013, 15, 18530-18538.

294. C. Hennig and S. Schmatz, Physical Chemistry Chemical Physics, 2016, 18, 19668-19675.

295. J. M. Bowman and A. F. Wagner, in The Theory of Chemical Reaction Dynamics, ed. D. C. Clary, Reidel, Dordrecht, 1985, pp. 47-76.

296. R. B. Walker and E. F. Hayes, in The Theory of Chemical Reaction Dynamics, ed. D. C. Clary, Reidel, Dordrecht, 1985, pp. 105-134.

297. Q. Sun and J. M. Bowman, The Journal of Chemical Physics, 1990, 92, 5201-5210.

298. W. H. Miller, N. C. Handy and J. E. Adams, The Journal of Chemical Physics, 1980, 72, 99.

299. D. Lauvergnat, A. Nauts, Y. Justum and X. Chapuisat, The Journal of Chemical Physics, 2001, 114, 6592-6604.

300. R. M. Marshall, H. Purnell and P. W. Satchell, Journal of Chemical Society, Faraday Transactions 1, 1984, 80, 2395-2403.

301. R. M. Marshall, H. Purnell and A. Sheppard, Journal of Chemical Society, Faraday Transactions 2, 1986, 82, 929-935.

302. S. Pratihar, X. Ma, Z. Homayoon, G. Barnes, L. and W. L. Hase, Journal of the American Chemical Society, 2017, 139, 3570-3590.

303. J. G. López, G. Vayner, U. Louderaj, S. V. Addepalli, S. Kato, W. A. deJong, T. L. Windus and W. L. Hase, Journal of the American Chemical Society, 2007, 129, 9976-9985.

304. U. Louderaj, K. Song, T. L. Windus, Y. Zhuang and W. L. Hase, The Journal of Chemical Physics, 2007, 126, 044105.

305. H.-G. Yu and J. S. Francisco, The Journal of Physical Chemistry A, 2009, 113, 3844-3849.

306. T. J. Preston, G. T. Dunning, A. J. Orr-Ewing and S. A. Vázquez, The Journal of Physical Chemistry A, 2014, 118, 5595-5607.

307. J. Xie, S. C. Kohale, W. L. Hase, S. G. Ard, J. J. Melko, N. S. Shuman and A. A. Viggiano, The Journal of Physical Chemistry A, 2013, 117, 14019-14027.

308. J. Xie, R. Sun, M. R. Siebert, R. Otto, R. Wester and W. L. Hase, The Journal of Physical Chemistry A, 2013, 117, 7162-7178.

309. J. Zhang, j. Xie and W. L. Hase, The Journal of Physical Chemistry A, 2015, 119, 12517-12525.

310. M. J. Cohen, N. C. Handy, R. Hernandez and W. H. Miller, Chemical Physics Letters, 1992, 192, 407-416.

311. W. H. Miller, The Journal of Chemical Physics, 1975, 62, 1899-1906.

312. W. H. Miller, R. Hernandez, N. C. Handy, D. Jayatilaka and A. Willetts, Chemical Physics Letters, 1990, 172, 62-68.

313. T. L. Nguyen and J. F. Stanton, The Journal of Chemical Physics, 2017, 147, 152704.

314. J. F. Stanton, The Journal of Phycial Chemistry Letters, 2016, 7, 2708-2713.

315. S. M. Greene, X. Shan and D. C. Clary, The Journal of Chemical Physics, 2016, 144, 244116.

316. S. M. Greene, X. Shan and D. C. Clary, The Journal of Chemical Physics, 2016, 144, 084113. 
317. R. E. Weston, T. L. Nguyen, J. F. Stanton and J. R. Barker, The Journal of Physical Chemistry A, 2013, 117, 821-835.

318. J. R. Barker, T. L. Nguyen and J. F. Stanton, The Journal of Physical Chemistry A, 2012, 116, 6408-6419.

319. T. L. Nguyen, J. F. Stanton and J. R. Barker, The Journal of Physical Chemistry A, 2011, 115, 5118-5126.

320. T. L. Nguyen, J. F. Stanton and J. R. Barker, Chemical Physics Letters, 2010, 499, 9-15.

321. V. Barone, The Journal of Chemical Physics, 2005, 122, 014108.

322. S. M. Greene, X. Shan and D. C. Clary, The Journal of Physical Chemistry A, 2015, 119, 12015-12027.

323. D. G. Truhlar, A. D. Isaacson and B. C. Garrett, in Theory of Chemical Reaction Dynamics, ed. M. Baer, CRC Press: Boca Raton, FL, 1985, vol. 4, pp. 65-137.

324. A. F. Wagner, The Journal of Physical Chemistry A, 2013, 117, 13089-13100.

325. C. Ridders, Advances in Engineering Software, 1982, 4, 75-76.

326. I. R. Craig and D. E. Manolopoulos, The Journal of Chemical Physics, 2004, 121, 3368-3373.

327. I. R. Craig and D. E. Manolopoulos, The Journal of Chemical Physics, 2005, 123, 034102.

328. Y. V. Suleimanov, R. Collepardo-Guevara and D. E. Manolopoulos, The Journal of Chemical Physics, 2011, 134, 044131.

329. Y. Li, Y. V. Suleimanov, J. Li, W. H. Green and H. Guo, The Journal of Chemical Physics, 2013, 138, 094307.

330. Q. Meng, J. Chen and D. Zhang, The Journal of Chemical Physics, 2015, 143, 101102.

331. Q. Meng, J. Chen and D. Zhang, The Journal of Chemical Physics, 2016, 144, 154312.

332. E. Gonzalez-Lavado, J. C. Corchado, Y. V. Suleimanov, W. H. Green and J. Espinosa-Garcia, The Journal of Physical Chemistry A, 2014, 118, 3243-3252.

333. Q. Meng, K. M. Hickson, K. Shao, J.-C. Loison and D. Zhang, Physical Chemistry Chemical Physics, 2016, 18, 29286-29292.

334. Y. Li, Y. V. Suleimanov, W. H. Green and H. Guo, The Journal of Physical Chemistry A, 2014, 118, 1989-1996.

335. Y. V. Suleimanov and J. Espinosa-García, The Journal of Physical Chemistry B, 2016, 120, 1418-1428.

336. J. W. Allen, W. H. Green, Y. Li, H. Guo and Y. V. Suleimanov, The Journal of Chemical Physics, 2013, 138, 221103.

337. D. J. Arseneau, D. G. Fleming, Y. Li, J. Li, Y. V. Suleimanov and H. Guo, The Journal of Physical Chemistry B, 2016, 120, 1641-1648.

338. Q. Meng and J. Chen, The Journal of Chemical Physics, 2017, 146, 024108.

339. M. M. Kermani and A. Maghari, Adsorption, 2017, 25, 663-669.

340. G.J. Kroes, Physical Chemistry Chemical Physics, 2012, 14, 14966-14981.

341. R. Welsch, K. Song, Q. Shi, S. C. Althorpe and T. F. Miller III, The Journal of Chemical Physics, 2016, 145, 204118. 